\title{
Psychometric properties of the Specific Thalassemia Quality of Life Instrument for adults
}

\author{
This article was published in the following Dove Press journal: \\ Patient Preference and Adherence \\ 30 June 2012 \\ Number of times this article has been viewed
}

\author{
Georgios N Lyrakos ${ }^{1,2}$ \\ Demetra Vini ${ }^{2}$ \\ Helen Aslani \\ Marouso Drosou-Servou² \\ '2nd Department of Anesthesiology, \\ School of Medicine, University of \\ Athens, Pain Clinic, Attikon University \\ Hospital, ${ }^{2}$ Thalassemia Unit, General \\ Hospital of Nikaia Ag. Panteleimon, \\ Athens, Greece
}

Background: No specific questionnaire has been developed to assess the health-related quality of life of thalassemia patients. Thus, the main objective of this study was to develop, according to psychometric standards, a self-administered Specific Thalassemia Quality of Life Instrument (STQOLI) for adult patients.

Methods: First, a qualitative phase was conducted to generate items and identify domains using the critical analysis incident technique and a literature review. A list of easily comprehensible, non-redundant items was defined using the Delphi technique and a pilot study on ten thalassemia patients. This phase involved both patients and experts. The second step was a quantitative validation phase comprising a study of 128 thalassemia patients in a single hospital. It was designed to select items, identify dimensions, and measure reliability and internal and concurrent validity. The psychometric and scaling properties of the proposed 41-item Specific Thalassemia Quality of Life Instrument were then assessed among patients recruited from the Thalassemia Unit at the General Hospital of Nikaia, Greece.

Results: The final questionnaire had 41 items comprising four main domains and one global item about general health. The factorial structure was satisfactory (loading $>0.40$ on each factor of the four domains for all items). Interscale correlations ranged from 0.06 to 0.78 , Cronbach's $\alpha$-coefficients were 0.78 for the psychosocial domain, 0.77 for the chelation domain, 0.72 for the transfusion domain, 0.81 for the disease and symptoms domain, and 0.840 for the total score of the questionnaire.

Conclusion: The 41-item Specific Thalassemia Quality of Life Instrument seems to be a valid tool for assessing health-related quality of life for patients with thalassemia. More research is needed to explore the universal properties of the questionnaire.

Keywords: quality of life, thalassemia, measurement, chelation, transfusion, validation

\section{Introduction}

Thalassemia is an inherited blood disease. It is a serious public health problem throughout the Mediterranean region, Middle East, and Indian subcontinent, as well as in Southeast Asia. ${ }^{1}$

Advances in biomedical science and technology have resulted in dramatic improvements in the health care of this condition. With enhanced survival, health-related quality of life (HRQOL) issues have become more prominent. ${ }^{2} \beta$-thalassemia is the most common form of hemolytic anemia ${ }^{3}$ and, each year, approximately 60,000 babies with thalassemia are born worldwide. ${ }^{4}$ With the availability of better transfusion regimens, iron chelation therapy, proper management of complications, and good supportive care, it is now possible for patients with thalassemia to have a near normal life span with a good HRQOL. ${ }^{3}$
Correspondence: Georgios N Lyrakos 46 Ofryniou Street, Nikaia,

I8454 Greece

Tel +30 21 104915426

Mobile +30694554 2073

Fax +30210 491 5426

Email geolyr@hotmail.com 
The impact of thalassemia major (TM) and thalassemia intermedia (TI) and their associated complications on quality of life (QoL) are largely unknown. Due to the fact that patients with TM have good survival rates because of the development of new treatments and better clinical management, ${ }^{5-9}$ we need to explore issues relating to QoL further.

Increased patient survival is accompanied by significant ongoing health care needs related to the chronic condition. ${ }^{10}$ Simply surviving is not sufficient; the quality of survival has emerged as a fundamental focus of comprehensive health care. ${ }^{11}$ Determining the degree of health impairment as perceived by the patient is essential information needed to recommend suitable therapy; therefore, HRQOL should now be considered an important index of effective health care in thalassemia. However, there is very little published work on the evaluation of QoL in patients with thalassemia. ${ }^{12}$ A PubMed search between 1990 and 2012, using the terms thalassemia AND quality of life AND/OR health-related, identified only 20 articles concerning QoL in thalassemia patients. ${ }^{13-32}$ One study used a semi-structured interview to access the psychosocial adjustment of adolescents and young adults ${ }_{13}^{13}$ another explored the social integration of older thalassemic patients, ${ }^{14}$ and a third studied the impact of neocyte transfusion in the management of thalassemia. ${ }^{15}$

A pilot study on QoL, as reflected by the psychosocial adjustment of children with TM undergoing iron chelation treatment, used the PedsQL 4.0 Generic Core Scales. ${ }^{16}$ The same measure was used in two additional articles in children ${ }^{17,18}$ and the Dartmouth Primary Care Cooperative Information Chart System questionnaire was used in another study. ${ }^{19}$

There was a cross-sectional study on adult patients with transfusion- and iron chelation-independent $\mathrm{TI}$ and $\mathrm{TM}^{20}$ and three studies in young adults using the Short Form 36 (SF-36). ${ }^{21-23}$ SF-36 is the most utilized measurement, but it is not specific for thalassemia patients. Two out of the 20 studies used interviews to assess QoL in patients under different chelation treatments ${ }^{24,25}$ and one was a review of the life of thalassemia patients. ${ }^{26}$

Among the remaining articles, two studies concerned parents, ${ }^{27,28}$ two studies were brief reports, ${ }^{29,30}$ one study was an international survey of patients with TM and their views about sustaining life-long desferrioxamine use, ${ }^{31}$ and the last article described the burden of TM and its treatment in terms of prevalence of iron-overload-related complications, direct and indirect costs, and patient physical and social well-being with a survey. ${ }^{32}$ Results from the literature review revealed that there were no specific QoL instruments. ${ }^{35}$
While a generic HRQOL instrument must be multidimensional, consisting, at a minimum, of the physical, psychological (including emotional and cognitive), and social health dimensions delineated by the World Health Organization, ${ }^{33,34}$ disease-specific measures may enhance measurement sensitivity for health domains germane to a particular chronic condition.

The lack of research relating to QoL in this population may be due in part to the lack of tools available to accurately measure HRQOL in patients with thalassemia. There are currently no thalassemia-specific scales for measuring QoL, and it has long been established that generic questionnaires may be insensitive to the unique experience of a patient with thalassemia. ${ }^{11}$ Similarly, it has been demonstrated that QoL may vary among different chelation treatments. ${ }^{36}$ In light of these considerations, there is a clear need to develop and validate a disease-specific QoL inventory for patients with thalassemia. Without access to a valid tool for measuring and comparing levels of QoL in this population and for tracking patient acceptance of therapies, there is little hope for developing better treatment modalities that will allow better management of the disease. Thus, a project to develop and validate a measure of HRQOL for thalassemia was undertaken.

Our hypotheses were generated based on patient and expert interviews to develop a disease-specific instrument. The main objective of our study was to develop a Specific Thalassemia Quality of Life Instrument (STQOLI) in order to assess HRQOL in these patients, according to psychometric standards, which could be used to compare patient QoL over time and thus in a longitudinal comparison. ${ }^{37}$ The questionnaire needed to be brief, understandable, and easy to complete for outpatients aged 18 years or older in Thalassemia Transfusion Units. It was designed to be self-administered. The final version, originally in Greek, is being adapted in English for the purposes of this paper.

The translation strategy was based on minimal criteria developed by the Scientific Advisory Committee of the Medical Outcomes Trust. ${ }^{38}$ Translation was performed using the multiple forward and backward translation protocol recommended by Guillemin et al. ${ }^{39}$ Following these, two independent bilingual health professionals translated the questionnaire into English (forward translation). The mother tongue of all translators was the Greek language and their level of English was advanced. A reconciliation meeting was conducted to obtain a consensus version. Then, one native Greek speaker who was blinded to the original version retranslated the re-conciliated English version into the source 
language (back translation), which is the recommended procedure for creating semantic equivalence. ${ }^{40}$ The back translation was revised by the authors, formulating the revised English version of the STQOLI. The results of the qualitative research that comprised the development phase of the STQOLI are presented here.

\section{Methods}

\section{Questionnaire development}

Phase I: drafting and pre-piloting of the questionnaire

The method we followed used the basic principles for survey design, suggested by de Vaus. ${ }^{41}$ This required the definition of a conceptual basis of the questionnaire before designing the specific questions. To archive this, a qualitative phase was conducted to generate items and identify domains using critical incident technique (CIT) analysis ${ }^{42}$ and a literature review.

In health care research, CIT analysis can be a good resource for identifying the experiences of a patient in the health care setting, exploring the dimensions of patientprovider interactions, and determining patient responses to illnesses and treatments.

The advantages of CIT analysis are that it is a flexible method that can be used to improve multi-user systems. Data are collected from the respondent's perspective and in his or her own words. It does not force respondents into any given framework. It identifies even rare events that might be missed by other methods that focus only on common and everyday events. CIT analysis is useful when problems occur, but the cause and severity of such problems are unknown. It is inexpensive and provides rich information. It emphasizes the features that will make a system particularly vulnerable, offers major benefits (eg, safety), and can be applied using questionnaires or interviews.

A health psychologist conducted eight individual semistructured interviews with recent outpatients using CIT analysis. ${ }^{42}$ Subjects were asked to detail specific factors, which according to them had an influence on their QoL. Each interview lasted 30 minutes on average. All the different wordings of a given idea were written on a form. Interviews were transcribed and items were generated from the verbatim statements ( $\mathrm{n}=40$ items).

The incidents were identified from the transcriptions and categorized by the research team. With each case, new categories and subcategories were derived from the data. This process of developing categories grounded in the data follows the principles laid down by Flanagan. ${ }^{42}$ This will form the basis of a classification of factors influencing QoL in patients with thalassemia.

\section{Participants}

Patients were recruited by the specialists who worked in the Transfusion Unit of the General Hospital of Nikaia. In order to complete the targeted sample, three patients were recruited from the list of appointments for laboratory tests, and five were recruited from the daily transfusion list. Participants had to be over 18 years old, have a definite diagnosis of transfusion-dependent thalassemia, and be able to understand and speak Greek fluently. They were asked to provide written consent for their participation in the study. Patients with psychotic or psychiatric diseases were excluded from the study. To ensure a broad spectrum of patients, the population was to include different patients with different marital status and different levels of education.

\section{Critical incidents}

The eight cases generated 16 incidents (mean: two per case, range: two to five). Ideally, collection of data should have continued until no new categories were generated, ${ }^{43}$ but with our small number of cases, the coding was not complete. Nonetheless, the incidents formed natural clusters. The most common factors identified in incidents were "chelation therapy," "transfusion," "complications," and "I feel bad or good" (mean 7; standard deviation [SD] 1) Other factors included, among others, "lack of leisure time," "sleeping problems," "fear for blood units," "sexual problems," "pain from the chelation procedure," "the loss of friends," "fear of the knowledge of the disease in the working environment," and "many complications."

\section{Literature review}

The domains that were found to be affected based on the literature review were physical deformity, growth retardation, and delayed puberty due to TM; ${ }^{11,29,35}$ physical appearance, eg, bone deformities and short stature, which contribute to a poor self-image, ${ }^{11,35}$ severe complications, such as heart failure, cardiac arrhythmia, liver disease, endocrine complications, and infections; ${ }^{4,31}$ physical, emotional, social, and school or work functioning; ${ }^{11,19,23,29,44-46}$ impact of iron chelation therapy and regular blood transfusions that require frequent visits to the hospital; ${ }^{47}$ and pain. ${ }^{45}$

The items were then coded in the four main dimensions that arose from CIT analysis: disease, chelation therapy, transfusion, and psychosocial dimension. The 16 incidents and the 17 factors from the literature review were discussed and were spread in semantic order to build the items to cover all the factors for the four domains. At this phase, a first version of the questionnaire was constructed (60-item version). The first version of the questionnaire to be piloted 
included one to three questions about each topic, depending on how complex and relevant the topics seemed.

\section{Phase II: a quantitative phase comprising 2 steps}

During the first step, this version was pre-piloted with ten thalassemia patients to establish face validity, during which time they were asked to comment on omissions or irrelevant items. Comments on face validity were received from 13 experts (three hematologists [MD], four nurses, two psychiatrists, two psychologists, and two social workers) who were set up to provide expert input on all stages of development for the questionnaire and to work with a team of questionnaire specialists. Their input consisted of creating a conceptual model, making choices to optimize the questionnaire development process, validating the results at each critical step of development, and providing final decisions on subsequent procedures.

This first step provided a shortened version of the questionnaire (50-item version). This resulted in some rewording and additional questions - for example, "patient satisfaction with the medical and nursing staff." The pilot questionnaire had five attitudinal questions dealing with the following topics that were not answered by the patients: "satisfaction with the staff", "sexual maturity," and "food"; the experts committee decided that they overlapped with other existing items. In order for an item to be excluded from the questionnaire at this step, the majority (eight of 13) of the expert committee had to agree.

Respondents were asked to respond on a five-item Likert scale $^{46}$ (extremely influences my QoL, influences my QoL quite a bit, moderately influences my QoL, influences my QoL a little bit, and does not influence my QoL) to each statement. Several questions (12/44) were phrased negatively to prevent "response acquiescence," defined as the tendency to agree rather than disagree. ${ }^{47}$

All patients found the attributes in the questionnaire relevant, and they agreed that the most important characteristics were the four main dimensions that arose from CIT analysis. Participants thought the questionnaire was of proper length, comprehensive, informative, and consistent (data not shown). This added to the experts' opinion that the questionnaire should have four facets that could be measured independently for longitudinal use and a total score for QoL as a tool for research use.

Second, a replication validation phase to corroborate results from the previous steps in a large sample provided the final 41-item questionnaire (available upon request). This second step was a quantitative validation phase comprising a study in a single hospital (General Hospital of Nikaia Greece) of a group of 150 thalassemia patients. Of these patients, 128 ( $85.3 \%$ participation rate) returned their completed questionnaires to the researchers. It was designed to select items, identify dimensions, and measure reliability and internal and concurrent validity.

The sample size was calculated to be representative of the Greek thalassemia population, which is estimated to be 2900 patients, assuming a confidence level of $95 \%$ and an accuracy level that would only tolerate a difference of 0.08 . The sample size was estimated at 114 patients, but assuming a $10 \%$ level of missing data, we aimed to recruit 128 patients.

The inclusion criteria for patients were as follows: (1) having a definite diagnosis of transfusion-dependent thalassemia, and (2) being able to understand the questions on the HRQOL questionnaires. Patients were excluded if they did not speak Greek fluently, had any severe psychiatric illness, and/or were taking part in clinical trials.

Randomization involved a random starting point on a list and then proceeded with the selection of every third element from then onwards. The starting point was not automatically the first on the list, but was instead randomly chosen from within the first to the third elements in the list of patients who had a transfusion appointment or an appointment for clinical tests.

To be consistent with most published relevant work on health measurement scales, we used parametric tests ${ }^{48}$ where possible. Reported $P$-values for differences according to gender, age, education, location, and marital status were considered significant at $P<0.05$. Analyses were performed using SPSS 16.0 (IBM Corporation, Armonk, NY).

\section{Item selection}

A first selection of items was made from the descriptive response distribution for each item. The criteria used to guide item selection/deletion were as follows: high rates of nonresponse and "not applicable" response $(\geq 20 \%)$, except for items where high rates in this response category were expected, ceiling, and floor effects ( $\geq 50 \%$ ), and unacceptable test-retest reliability (weighted $\kappa$-coefficient $<0.60$ ).

Floor and ceiling effects determined whether a disproportionately large percentage of responders were prone to providing either the lowest or highest values. If an item had more than half the answers in the "extremely" or "not at all" categories, the expert committee had to decide the remaining item in the questionnaire. 
Out of 50 patients randomly selected as a convenience subsample of the original sample to facilitate evaluation of external (test-retest) reliability for the total score of the measurement, eventually 48 participated (4\% dropout). Cronbach's $\alpha$ for this subset at the initial test period was 0.83 , and remained the same at the retest period five days after the first assessment $(\alpha=0.83)$. Correlation between the test and retest mean score of these participants was likewise very high ( $\mathrm{r}=0.89 ; P<0.001)$, suggesting that test-retest reliability was very good for the total score of the STQOLI.

Pragmatic considerations also tempered selection: interest of the item in itself, number of items covering the same domain, and redundancy. Results showed that the proportion of missing responses per item was low. This first selection led to the deduction of ten items.

\section{Validation process}

Analyses of the relationship between independent variables and HRQOL were performed to establish those variables associated with HRQOL. Exploratory factor analysis using principal axis factoring with an orthogonal (varimax) rotation was conducted on the sample for each domain independently for sampling reasons.

\section{Procedure}

All participants were recruited voluntarily from the Thalassemia Unit at the General Hospital of Nikaia, Greece. The Ethics Committee and the scientific board of the General District Hospital of Nikaia were informed of the purpose of the study and the confidentiality and anonymity of the process and approved the research protocol.

We used systematic sampling, which relies on arranging the target population according to some ordering scheme and then selecting elements at regular intervals through that ordered list. Using this procedure, each element in the population has a known and equal probability of selection. This makes systematic sampling functionally similar to simple random sampling. It is, however, much more efficient (if variance within the systematic sample is more than variance of the population). In our case, it involved a random start and then proceeded with the selection of every $\mathrm{k}_{\mathrm{th}}$ element from then onwards. In this case, $\mathrm{k}=$ population size/sample size. The starting point was not automatically the first in the list, but was instead randomly chosen from within the first to the third element in the list of patients who had a transfusion appointment or an appointment for clinical tests.

After giving written informed consent, patients who took part in the procedure completed a questionnaire on demographic and clinical characteristics along with a battery of tests including STQOLI and the Short Form 12 Patient Questionnaire (SF-12), ${ }^{49,50}$ the Greek version of the Depression Anxiety Stress Scale (DASS), ${ }^{51}$ Greek Life Orientation Test - Revised (GrLot-R), ${ }^{52}$ the Rosenberg Self-Esteem Scale (SES), ${ }^{53}$ and the Satisfaction with Life Scale (SWLS). ${ }^{54}$

It was hypothesized that both the Mental Composite Score (MCS) and Physical Composite Score (PCS) would be moderately correlated with the STQOLI total and the four domain scores. Specifically, patients who reported a greater score in the disease and symptoms domain and better global health were also hypothesized to report a higher psychical score in the SF-12, while patients who reported a greater score in the psychosocial domain and better global health were also hypothesized to report a higher mental score in the SF-12. On the other hand, since optimism is a factor affecting QoL, it was hypothesized that GrLOT-R would correlate more highly with the psychosocial domain of the STQOLI and less with the disease and symptoms domain. SES was hypothesized to correlate with the items concerning the effect in body image. Depression, anxiety, and stress were hypothesized to correlate moderately but negatively with the STQOLI total and the four domains scores, since higher scores in the STQOLI factors means better QoL, while the higher a score is in DASS scales, the more symptoms a patient has. Finally it was hypothesized that the SWLS scale would be moderately correlated with the STQOLI total and the four domains scores.

\section{Data analysis}

The final questionnaire had 40 items comprising four main domains, plus one global item about the current state of health and general health.

The 40 items in the four domains were as follows:

1. Disease and symptoms, with 12 items;

2. Chelation therapy, with 13 items (five items per os chelation therapy users, five items for subcutaneous chelation therapy users, and three common items);

3. Psychosocial impact, with ten items;

4. Transfusion impact, with five items.

Current QoL was assessed by patient response in each domain. Both overall QoL and subscales were measured with a scale from 0 to 100 , with higher values indicating better quality for each scale. Satisfaction with chelation therapy was assessed with two items that were excluded from the final STQOLI for reasons outlined in the Results section. The questionnaire also contained sociodemographic variables, 
including age, sex, educational level, professional status, and marital status.

General characteristics of the patients are presented in terms of percentage, mean, and SD. For HRQOL, both total STQOLI score and summary scores were presented in terms of mean and SD. HRQOL scores based on self-reporting both for the new questionnaire and the rest of the scales are presented in Table 1.

The normality of the items of all measures was investigated and found to be within the level recommended for confirmatory and exploratory factor analysis with maximumlikelihood estimation (skewness $\backslash 2$, kurtosis $\backslash 7)^{55}$ and still within acceptable values for normality. ${ }^{56}$

The psychometric properties of the STQOLI were analyzed as follows: (a) principal component analysis with an orthogonal (Varimax) rotation was utilized to assess the internal structure of the measure; (b) internal consistency reliability of the instrument was assessed using Cronbach's $\alpha$ coefficient, ${ }^{57}$ and corrected item-total correlations; and

Table I Descriptive summary scores for the quality of life (QoL) factors and the Depression Anxiety Stress Scale (DASS); anxiety, stress, and depression scales; Greek Life Orientation Test-Revised (GrLot-R); Satisfaction with Life Scale (SWLS); Rosenberg SelfEsteem Scale (SES); and age

\begin{tabular}{|c|c|c|c|c|c|}
\hline & $\operatorname{Min} / \max *$ & Min & Max & $\mathbf{x}$ & SD \\
\hline Age & & 20 & 62 & 37.2 & 9.5 \\
\hline Disease and symptoms D & $0-100$ & 30 & 84.2 & 62.9 & 12.8 \\
\hline Psychosocial D & $0-100$ & 36 & 100 & 72.4 & 14.8 \\
\hline Transfusion D & $0-100$ & 24 & 96 & 68.4 & 17.4 \\
\hline Chelation therapy D & $0-100$ & 46 & 99.9 & 77.3 & II.7 \\
\hline STQOLI total score & $0-100$ & 46 & 89.4 & 71.4 & 10.8 \\
\hline Chelation satisfaction & $0-100$ & 20 & 100 & 76.3 & 18.2 \\
\hline $\begin{array}{l}\text { Limitation from disease } \\
\text { and complications }\end{array}$ & $0-100$ & 31 & 100 & 72.6 & 16.7 \\
\hline Effect in daily activities & $0-100$ & 20 & 100 & 77.2 & 21.1 \\
\hline Mental health & $0-100$ & 20 & 100 & 73.3 & 20.5 \\
\hline Chronicity effect & $0-100$ & 5 & 100 & 77.9 & 18.9 \\
\hline Effect in sexual life & $0-100$ & 6.7 & 100 & 74.3 & 25.8 \\
\hline Effect in body image & $0-100$ & 6.7 & 100 & 67.3 & 22.8 \\
\hline Pain and fatigue & $0-100$ & 20 & 100 & 79.6 & 18.4 \\
\hline $\mathrm{PCSI} 2$ & $0-100$ & 23.5 & 63.4 & 46.4 & 10.7 \\
\hline MCSI2 & $0-100$ & 17.7 & 62.2 & 46.4 & II.I \\
\hline Optimism (GrLOT-R) & $0-24$ & 6 & 24 & 14.8 & 3.8 \\
\hline Depression (DASS) & $0-42$ & 00 & 34 & 6.8 & 8.5 \\
\hline Anxiety (DASS) & $0-42$ & 00 & 32 & 6.1 & 7.1 \\
\hline Stress (DASS) & $0-42$ & 00 & 41 & 10.8 & 8.6 \\
\hline $\begin{array}{l}\text { Rosenberg self-esteem } \\
\text { scale (SES) }\end{array}$ & $10-40$ & 14 & 37 & 27.8 & 3.2 \\
\hline $\begin{array}{l}\text { Satisfaction with life } \\
\text { scale (SWLS) }\end{array}$ & $5-35$ & 5 & 35 & 21.7 & 7.5 \\
\hline
\end{tabular}

Notes: $*$ The possible minimum and maximum for each measure. Valid $\mathrm{n}=128$. Abbreviations: D, domain; Min, minimum; Max, maximum; $x$, mean; MCS, mental composite score; PCS, physical composite score; SD, standard deviation. (c) convergent validity was assessed by examining the relationships using a Pearson's product-moment correlation between the STQOLI and SF-12, which was used for analysis with this group of patients to compare the physical and mental composite score with the four new domains of STQOLI. This was decided since the developers have consequently suggested that a 12-item sub-set of the original 36 items of the SF-36 can be used to construct a shorter health survey, which can produce PCS and MCS without substantial loss of information. ${ }^{49,50}$

The Greek versions of DASS, ${ }^{51}$ the GrLOT-R, ${ }^{52}$ SES, ${ }^{53}$ and the SWLS ${ }^{54}$ were also administered to test the convergent and discriminant validity.

The primary purpose of the exploratory factor analysis (EFA) is to arrive at a more parsimonious conceptual understanding of a set of measured variables by determining the number and nature of common factors needed to account for the pattern. Assuming that identifying latent variables that account for the correlations among measured variables is the goal of the research project, a researcher must then decide if an exploratory or confirmatory approach will be used. Both (EFA) and confirmatory factor analysis (CFA) are based on the common factor model, and both seek to represent the structure of correlations among measured variables using a relatively small set of latent variables.

However, EFA is primarily a data-driven approach. No a priori number of common factors is specified and few restrictions are placed on the patterns of relations between the common factors and the measured variables (ie, the factor loadings). EFA provides procedures for determining an appropriate number of factors and the pattern of factor loadings primarily from the data. In situations like ours, in which research was conducted for the first time, and in which a researcher has relatively little theoretical or empirical basis to make strong assumptions about how many common factors exist or what specific measured variables these common factors are likely to influence, EFA is probably a more sensible approach than CFA. EFA is likely to be more desirable in these situations because the number of plausible alternative models might be so large that it would be impractical to specify and test each one in CFA.

Additionally, when a strong basis does not exist for identifying a single model or a few specific competing models, it is quite possible that a researcher might fail to identify a number of plausible models. Therefore, in this context, the data-driven approach of EFA seems preferable.

To evaluate the principal component analysis, clusters of items were observed and interpreted. Criteria for retaining 
extracted component(s) included the following: (a) eigenvalue of one or greater; ${ }^{58}$ (b) percentage of variance accounted for by the retained component(s); and (c) scree plot. ${ }^{59}$ Item-component correlations of 0.4 and above were retained. Alpha-coefficients of 0.70 or higher and corrected item-total correlations higher than 0.40 were deemed to indicate good reliability. ${ }^{60,61}$

\section{Other measurements}

DASS- $42^{62,63}$ is a quantitative measure of distress on the basis of three subscales of depression, anxiety (eg, symptoms of psychological arousal), and stress (eg, cognitive, subjective symptoms of anxiety). We used the Greek validated tool of DASS-42. ${ }^{51}$ Each subscale has 14 questions that respondents answered according to a Likert-type scale ranging between 0 ("does not apply to me at all") to 3 ("applies to me very much, or most of the time").

The LOT ${ }^{64}$ was developed to assess individual differences in generalized optimism versus pessimism. This measure, and its successor the LOT-R, have been used in a good deal of research on the behavioral, affective, and health consequences of this personality variable. The revised scale was constructed in order to eliminate two items from the original scale, which dealt more with coping style than with positive expectations for future outcomes. The correlation between the revised scale and the original scale is 0.95 . The GrLOT-R is a very brief measure that is easy to use. Its brevity makes it ideal for use in projects in which many measures are being used. It should be noted that this is a research instrument, not intended for clinical applications. There are no "cut-offs" for optimism or pessimism and it is used as a continuous dimension of variability. ${ }^{52}$

The Rosenberg SES is a ten-item self-report measure of global self-esteem. It consists of ten statements related to overall feelings of self-worth or self-acceptance. The items are answered on a four-point scale ranging from "strongly agree" to "strongly disagree." The SES has also been administered as an interview. ${ }^{53}$

The SWLS is a measure of life satisfaction developed by Diener et al. ${ }^{54}$ Life satisfaction is one factor in the more general construct of subjective well-being. Theory and research from fields outside rehabilitation have suggested that subjective well-being has at least three components: positive affective appraisal, negative affective appraisal, and life satisfaction. Life satisfaction is distinguished from affective appraisal in that it is more cognitively than emotionally driven. Life satisfaction can be assessed specific to a particular domain of life (eg, work, family) or globally.
The SWLS is a global measure of life satisfaction. The SWLS consists of five items that are completed by the individual whose life satisfaction is being measured.

\section{Results \\ Descriptive statistics}

Out of the 150 patients who could participate, 128 returned the battery to the researchers $(85.3 \%$ participation rate). The sample consisted of 34 males $(26.6 \%)$ and 94 females (73.4\%). Their age ranged from 20 to 62 years, with a mean of 37.2. Twenty-five (19.5\%) had one to three children (mean 1.3), and 38 of the 128 (29.9\%) patients smoked three to 30 cigarettes per day (mean 14.5). Finally, 40 patients $(32.8 \%)$ had had a splenectomy. The mean and SD of the STQOLI and the subscales of the four domains along with the other measurements and the new factors that were revealed from the factor analysis are shown in Table 1. The domains and subdomains of the STQOLI are not mutually exclusive. In other words, if a patient reported low in the disease and symptoms domain and in the psychosocial domain, the patient would be counted in both categories. That is the reason why we have a $0-100$ score both for the four main domains of the questionnaire and the subdomains.

As can be seen in Table 1, PCS12 (mean $=46.4$; $\mathrm{SD}=10.7)$ and $\mathrm{MCS} 12($ mean $=46.4 ; \mathrm{SD}=11.1)$ were both lower from the normative data of the healthy Greek population $(50 \pm 10$ for both scores $){ }^{65}$

\section{Validation \\ Reliability analysis}

Cronbach's $\alpha$ and " $\alpha$ if item deleted" were calculated. Since $\alpha$ depends on the length of the scale (the number of questions) and the correlation of the items on the scale (actual reliability), the Spearman-Brown formula, where $\mathrm{k}$ is the number of items of the subscale divided by the number of items of the overall scale, ${ }^{66,67}$ was used to estimate expected subscale alphas:

$$
\alpha_{\text {subscale }}=\mathrm{k}_{\text {ascale }} /\left(1+(\mathrm{k}-1) \alpha_{\text {scale }}\right) .
$$

For reliability, the observed scale $\alpha$ should be $>0.70$ to be acceptable, $>0.80$ to be good, and $>0.90$ to be excellent, and observed subscale $\alpha$ values greater than expected. ${ }^{68}$

The average inter item correlations (coefficient $\alpha$-values) for the total scale were 0.840 and from 0.711 to 0.781 for the rest of the subdomains. $\alpha$-levels did not exceed Kline's criterion of 0.7 for internal consistency in any domain ${ }^{68}$ and were all higher than the expected $\alpha$ (Table 2 ). 
Table 2 Cronbach's $\alpha$ for the total score of Specific Thalassemia Quality of Life Instrument (STQOLI) and the four subscales

\begin{tabular}{|c|c|c|c|c|c|c|}
\hline Domains of STQOLI & Cronbach's $\alpha$ & $\begin{array}{l}\text { Expected } \\
\text { Cronbach's } \alpha\end{array}$ & $\begin{array}{l}\text { Corrected item } \\
\text { total correlations }\end{array}$ & $\begin{array}{l}\text { Factors } \\
\text { from EFA }\end{array}$ & $\begin{array}{l}\text { Total variance } \\
\text { explained } * *\end{array}$ & $\begin{array}{l}\text { Number } \\
\text { of items }\end{array}$ \\
\hline Disease and symptom ${ }^{\mathrm{a}}$ & 0.813 & 0.692 & $0.14 I-0.604$ & 3 & 57.312 & 12 \\
\hline Chelation therapy impact ${ }^{\mathrm{a}}$ & 0.767 & 0.679 & $0.110-0.701$ & 3 & 80.377 & 13 \\
\hline Transfusion impact ${ }^{\mathrm{a}}$ & 0.723 & 0.324 & $0.308-0.553$ & 2 & 69.048 & 5 \\
\hline Psychosocial impact $^{\mathrm{a}}$ & 0.782 & 0.612 & $0.277-0.644$ & 3 & 65.516 & 10 \\
\hline Total score ${ }^{\mathrm{a}}$ & 0.840 & & $0.290-0.955$ & & & 40 \\
\hline Chelation satisfaction & 0.808 & & 0.678 & I & 83.896 & 2 \\
\hline Chelation impact ICP* & 0.972 & 0.324 & $0.903-0.949$ & Ist & & 5 \\
\hline $\begin{array}{l}\text { Limitation from disease } \\
\text { and complications* }\end{array}$ & 0.823 & 0.391 & $0.46 \mathrm{I}-0.695$ & 2nd & & 7 \\
\hline Chelation impact ICT & 0.812 & 0.311 & $0.576-0.692$ & $3 r d$ & & 4 \\
\hline Effect in daily activities* & 0.835 & 0.297 & $0.594-0.710$ & 4 th & & 3 \\
\hline Mental health* & 0.829 & 0.297 & $0.654-0.7 \mid I$ & 5 th & & 3 \\
\hline Chronic effect* & 0.740 & 0.311 & $0.340-0.628$ & 6th & & 4 \\
\hline Effect in sexual life* & 0.727 & 0.297 & $0.524-0.569$ & 7th & & 3 \\
\hline Pain and fatigue* & 0.633 & 0.297 & $0.409-0.491$ & 8th & & 3 \\
\hline Effect from transfusion* & 0.632 & 0.297 & $0.385-0.509$ & 9th & & 3 \\
\hline Effect in body image* & 0.570 & 0.297 & $0.315-0.408$ & 10th & & 3 \\
\hline Splenectomy and somnolence* & 0.544 & 0.268 & 0.374 & IIth & & 2 \\
\hline
\end{tabular}

Notes: ${ }^{\text {TT }}$ The four quality of life domains; EFA was run independently for each due to the fact that each domain had items measuring different surface attributes. *The eleven factors revealed from the EFA in the total scale (40 items). **The variance explained is for the factor analysis for each domain independently.

Abbreviations: EFA, exploratory factor analysis; ICP, ion chelation pump; ICT, iron chelation tablets.

The fact that Cronbach's $\alpha$-coefficient for the total number of items was 0.84 indicates that the total scale has high internal consistency. We also observed that it was not necessary to delete any more of the items to improve the reliability score of the test since factor analysis had no items with complex structure that needed to be removed because they could not be categorized to a factor. Furthermore, based on the results from the first factor analysis, which indicated that each section included two to three factors accounting for more than $50 \%$ of variance, we found that even though none of the factors showed $\alpha<0.70$, some items showed suboptimal item-total correlation (either $<0.2$ or $>0.5$ ). The two items that were removed from the questionnaire were q4 and q5, which referred to satisfaction from the chelation therapy. Since Cronbach's $\alpha$ was sufficiently improved when items were removed, the omission of items from the scale was justified. Another two items that had a low inter-item correlation were $\mathrm{q} 38(\mathrm{r}=0.100)$ and $\mathrm{q} 36(\mathrm{r}=0.079)$. However, Cronbach's $\alpha$ did not improve sufficiently when these items were removed and thus omission of these items from the scale was not justified. Finally, the experts' committee decided that both items were important for the questionnaire and were kept in the questionnaire. Items that were loading poorly on both factors were erased. This led to the second factor analysis of the 40 items, in which eleven factors led to satisfactory item-total correlation. The results of the internal consistency for the factors of each domain and the eleven factors of the second factor analysis of the 40 items along with item-total correlations are presented in Table 3.

\section{Validity \\ Content validity}

Content validity, ie, whether the instrument provides adequate coverage of the topic, was addressed by the interviews that were conducted both with patients and experts in the first phase of this research. However, EFA was used to analyze interrelations among the items of the questionnaire. Due to the large number of questions, the exploratory factor analysis was the best way to recognize and explain the dimensions of the four domains. Thus, principal component analysis with orthogonal Varimax rotation was conducted to assess the internal structure of the measure.

Before performing the factor analysis, we checked whether the assumptions regarding the normality of the distribution were satisfied. Skewness and kurtosis were used as indicators of the normality among single variables. ${ }^{69,70}$

In this analysis, skewness and kurtosis were used as indicators of normality among single variables; one item (q36) was transformed because it did not satisfy the assumptions of normality. After that, we applied parametric statistics, consistent with published relevant work. ${ }^{56}$ To investigate the internal structure of the STQOLI (construct validity), five criteria were applied to determine how many factors should be retained for each subdomain: (a) the point of inflexion 


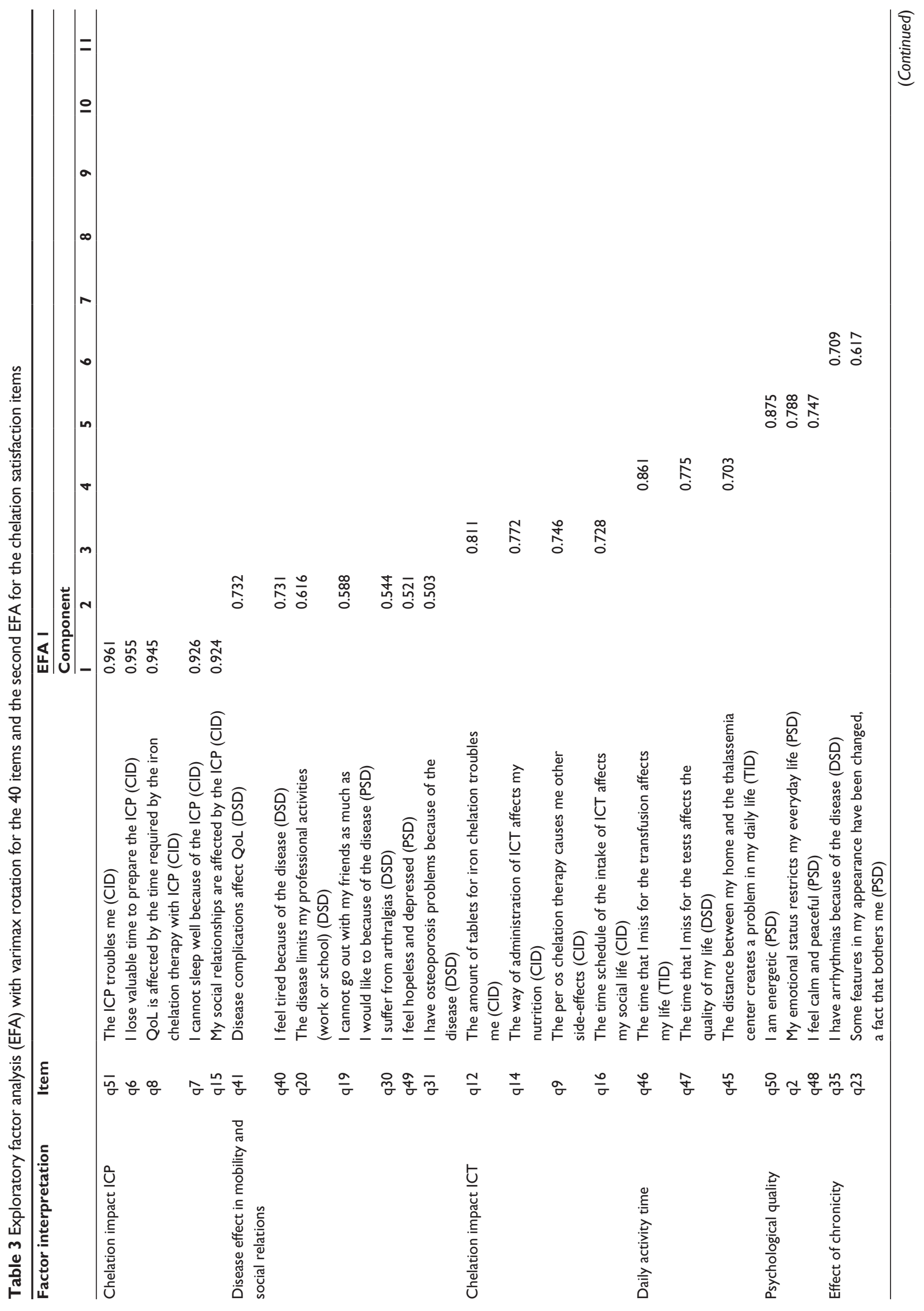




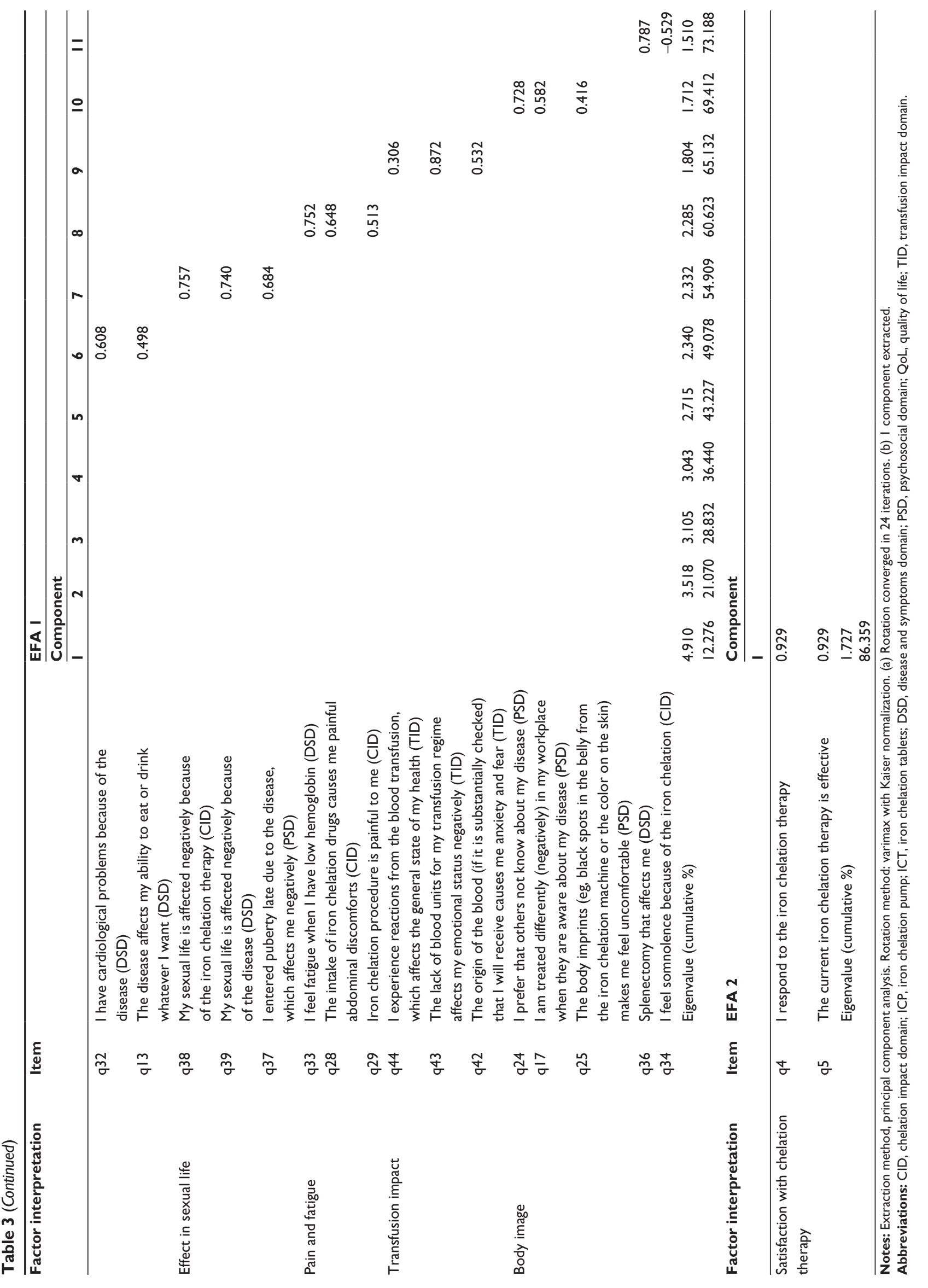


displayed by the scree plot; (b) the "eigenvalues $>1.0$ " criterion; (c) The "proportion of variance accounted for an approximate additional 5\% of the variance" criterion; (d) the interpretability criteria, which is that a given component should contain at least three variables with significant $(>0.40)$ loadings; variables loading on the same component should share the same conceptual meaning; and variables loading on different components should appear to measure different constructs; and (e) for the best solution in terms of interpretability and theoretical sensibility, solutions with up to two factors more and two factors less were also investigated.

Questions whose deletion increased the overall $\alpha$ and those that loaded $<0.40$ or loaded to two factors or were unexpectedly grouped in a factor were thoroughly examined.

\section{Factor analysis for each domain independently}

In the disease and symptoms domain, analysis identified three factors accounting for $57.14 \%$ of the variance. The first factor consisted of items q40, q41, q30, and q31, which included the limitations from the disease. The second factor consisted of items q32, q35, q33, q20, and q13, which referred to problems from the disease complications, while the third consisted of items q36 and q39. In the chelation impact domain, analysis identified three factors accounting for $80.38 \%$ of the variance. The first factor was loaded with items q51, q6, q8, q7, and q15, which referred to chelation therapy with a pump, the second with items q14, q9, q16, q12, and q28, which referred to oral chelation therapy and the third with q38, q29, and q34, which included the common questions for both therapies. In the psychosocial impact domain, analysis identified three factors accounting for $58.92 \%$ of the variance where the first factor was loaded with items q2, q50, q49, and q48, which referred to mental health, the second with q23, q37, q19, and q25, which referred to psychological impact due to the disease, and the third with items q17 and q24, which referred to the social effect due to the disease. Finally, the transfusion impact domain analysis identified two factors accounting for $69.52 \%$ of the variance where q41 and q40 were loaded in the first factor, explaining the psychological effect from the transfusion, and $\mathrm{q} 43, \mathrm{q} 42$, and $\mathrm{q} 44$ in the second factor, explaining the impact of transfusion in QoL.

\section{Factor analysis for the $\mathbf{4 0}$ items}

Factors loadings after rotation are reported in Table 3 . The analysis identified eleven factors accounting for $73.2 \%$ of the variance. The first factor was composed of all the items in the chelation therapy with a pump factor of the first EFA (q51, q6, q8, q7, and q15). The second factor was composed of four items from the disease limitations factor ( $q 40, q 41, q 30$, $\mathrm{q} 31$, and q20) and two items from the psychosocial domain referring to limitation in daily activities (q19) and feeling depressed (q49). The third factor was composed of four items of the oral chelation therapy domain (q12, q14, q9, and q16), while the fourth factor had the items from the transfusion factor (q46 and q45) and an item from the disease domain (q47), all referring to problems caused by time limitation. The fifth factor was composed of all the items in the mental health factor (q2, q50, and q48). The sixth factor consisted of all the items referring to the chronic problems caused by the disease (q35, q23, q32, and q13). The seventh factor contained three items (q38, q39, and q37) referring to sexual life. The eighth factor contained three items referring to pain and fatigue (q33, q28, and q29), while the ninth factor consisted of three items from the transfusion impact domain referring to the effect of blood transfusions. The tenth factor had two social items from the psychosocial impact domain (q24, q17) and an item referring to body image, which affects social relationships with others due to body imprints. Finally, the eleventh factor had only two items: one referring to the chronic problem of splenectomy (q36), and an item about sleep (q34).

\section{Construct validity}

\section{Scale and subscale intercorrelations}

The total STQOLI and SF-12 total scores (PCS12 and MCS12) correlated strongly and positively $(\mathrm{r}=0.551$ and 0.354; $P<0.001$ ) (Table 4), suggesting a substantial association between HRQOL in thalassemia (STQOLI) and generalized mental and physical HRQOL as it is measured with SF-12, although the coefficient indicates that the measures do not overlap completely.

Interscale correlations ranged from 0.141 to 0.701 for all domains (Table 2). The four domain scores correlated significantly and moderately with each other $(\mathrm{r}=0.301-0.645$; $P<0.001$ ) (Table 4). All domain scores were strongly related to the STQOLI total score $\left(\mathrm{r}_{\mathrm{CID}}=0.655, \mathrm{r}_{\mathrm{DSP}}=0.870\right.$, $\mathrm{r}_{\mathrm{PSD}}=0.761$, and $\mathrm{r}_{\mathrm{TID}}=0.781 ; P<0.001$, respectively), a result that agrees with Kline, ${ }^{68}$ according to whom "maximum validity ... is obtained where test items do not all correlate with each other, but where each correlates positively with the criterion. Such a test would have only low internalconsistency reliability."

All the other factors were correlated significantly and moderately with each other and the main domains 
Table 4 Pearson product-moment correlations for Specific Thalassemia Quality of Life Instrument (STQOLI) and the other measurements

\begin{tabular}{|c|c|c|c|c|c|c|c|c|c|c|}
\hline & CID & DSD & PSD & TID & $\begin{array}{l}\text { STQOLI } \\
\text { total } \\
\text { score }\end{array}$ & Limitation & $\begin{array}{l}\text { Effect in } \\
\text { everyday } \\
\text { activities }\end{array}$ & $\begin{array}{l}\text { Mental } \\
\text { health }\end{array}$ & $\begin{array}{l}\text { Effect of } \\
\text { chronicity }\end{array}$ & $\begin{array}{l}\text { Effect in } \\
\text { sexual life }\end{array}$ \\
\hline CID & I & & & & & & & & & \\
\hline DSD & $0.476 * *$ & 1 & & & & & & & & \\
\hline PSD & $0.429 * *$ & $0.645 * *$ & 1 & & & & & & & \\
\hline TID & $0.301 * *$ & $0.551 * *$ & $0.409 * *$ & I & & & & & & \\
\hline STQOLI total score & $0.655 * *$ & $0.870 * *$ & $0.76 I * *$ & $0.78 I * *$ & 1 & & & & & \\
\hline Limitation' & $0.33 I * *$ & $0.846 * *$ & $0.606 * *$ & $0.529 * *$ & $0.726 * *$ & I & & & & \\
\hline Everyday activities & $0.329 * *$ & $0.585 * *$ & $0.483 * *$ & $0.757 * *$ & $0.692 * *$ & $0.502 * *$ & I & & & \\
\hline Mental health & $0.26 I * *$ & $0.387 * *$ & $0.764 * *$ & $0.236 *$ & $0.507 * *$ & $0.398 * *$ & $0.215^{*}$ & 1 & & \\
\hline Effect of chronicity & $0.5 \mid 4^{* *}$ & $0.777 * *$ & $0.610 * *$ & $0.372 * *$ & $0.687 * *$ & $0.542 * *$ & $0.377 * *$ & $0.380 * *$ & 1 & \\
\hline Effect in sexual life & $0.350 * *$ & $0.562 * *$ & $0.50 I * *$ & 0.158 & $0.499 * *$ & $0.315 * *$ & $0.213 *$ & $0.266 * *$ & $0.413 * *$ & 1 \\
\hline Effect in body image & $0.319 * *$ & $0.381 * *$ & $0.778 * *$ & $0.33 I * *$ & $0.554 * *$ & $0.363 * *$ & $0.503 * *$ & $0.340 * *$ & $0.345 * *$ & $0.196 *$ \\
\hline Pain and fatigue & $0.682 * *$ & $0.596 * *$ & $0.458 * *$ & $0.497 * *$ & $0.743 * *$ & $0.45 I * *$ & $0.443 * *$ & $0.26 I * *$ & $0.516 * *$ & $0.269 * *$ \\
\hline Chelation satisfaction & $0.375 * *$ & $0.236 *$ & $0.418 * *$ & 0.062 & 0.188 & $0.225 *$ & 0.140 & $0.273 * *$ & $0.220 *$ & 0.176 \\
\hline PCSI2 & 0.158 & $0.670 * *$ & $0.416 * *$ & $0.519 * *$ & $0.55 I * *$ & $0.691 * *$ & $0.5 \mid 4^{* * *}$ & $0.257 * *$ & $0.348 * *$ & $0.191 *$ \\
\hline MCSI2 & 0.116 & $0.208 *$ & $0.626 * *$ & 0.184 & $0.354 * *$ & $0.354 * *$ & 0.043 & $0.840 * *$ & $0.286 * *$ & 0.100 \\
\hline Optimism & $0.3 \mid 2 * *$ & $0.378 * *$ & $0.524 * *$ & 0.145 & $0.354 * *$ & $0.373 * *$ & $0.203 *$ & $0.382 * *$ & $0.277 * *$ & $0.265 * *$ \\
\hline Depression & $-0.395 * *$ & $-0.360 * *$ & $-0.680 * *$ & $-0.26 I * *$ & $-0.455^{* *}$ & $-0.328 * *$ & $-0.255 * *$ & $-0.789 * *$ & $-0.336 * *$ & $-0.274 * *$ \\
\hline Anxiety & $-0.295 * *$ & $-0.247 *$ & $-0.63 I * *$ & $-0.293 * *$ & $-0.404 * *$ & $-0.3 I I * *$ & -0.179 & $-0.662 * *$ & $-0.284 * *$ & $-0.280 * *$ \\
\hline Stress & $-0.214^{*}$ & $-0.248 * *$ & $-0.664 * *$ & $-0.295 * *$ & $-0.437 * *$ & $-0.293 * *$ & $-0.237 *$ & $-0.732 * *$ & $-0.254^{* *}$ & $-0.238 *$ \\
\hline Self esteem & 0.065 & 0.051 & 0.107 & 0.039 & 0.068 & 0.006 & 0.103 & $0.195 *$ & -0.064 & -0.069 \\
\hline Life satisfuction & $0.228 *$ & $0.436 * *$ & $0.639 * *$ & 0.174 & $0.458 * *$ & $0.419 * *$ & $0.242 * *$ & $0.599 * *$ & $0.355 * *$ & $0.262 * *$ \\
\hline Age & -0.162 & $-0.390 * *$ & $-0.217 *$ & $-0.365 * *$ & $-0.270 *$ & $-0.477 * *$ & $-0.331 * *$ & $-0.237 *$ & $-0.389 * *$ & -0.122 \\
\hline
\end{tabular}

Notes: 'From disease and complications; *correlation is significant at the 0.05 level (2-tailed); **correlation is significant at the $0.0 \mathrm{I}$ level (2-tailed). Significant correlations are in bold. Light grey zone: interscale correlations for the subdomains of STQOLI. Dark grey zone: interscale correlations for the factor revealed from EFA the 40 items of the STQOLI.

Abbreviations: CID, Chelation impact domain; DSD, Disease and symptoms domain; MCS, Mental composite score; PCS, Physical composite score; PSD, Psychosocial domain QoL, Quality of life; TID, Transfusion impact domain.

( $\mathrm{r}=0.213$ to $0.777 ; P<0.05)$ with the exception of the transfusion impact domain that had no significant correlation with the effect in the sexual life factor $(r=0.158$; nonsignificant).

\section{Convergent and discriminant validity}

In order to examine the convergent validity of the total score of STQOLI and each domain independently, we also administered DASS, GrLOT-R, SES, and SWLS. Correlations between theoretically similar measures should be "high," while correlations between theoretically dissimilar measures should be "low."

To establish discriminant validity, you need to show that measures that should not be related are in reality not related. ${ }^{70}$

The strong and statistically significant correlation between MCS and the psychosocial impact domain $(\mathrm{r}=0.626 ; P<0.001)$ and PCS with the disease and symptoms domain $(\mathrm{r}=0.670 ; P<0.001)$ (Table 4$)$ show that the new measurement has a good convergent validity in the first two domains.
In favor of the questionnaire's good convergent validity was also the one-way between groups analysis of variance (ANOVA), which was conducted to explore the relationship between the four domains of the new questionnaire and the five categories of general health as it was described by the patients (exceptional, very good, good, fair, and bad), since we found a statistically significant difference in almost all the categories of general health compared to the quality domains of STQOLI. ANOVA revealed overall significant differences between the four groups on general health, with $P<0.001$ for the disease and symptoms domain, the transfusion domain, the psychosocial impact domain, and for the total STQOLI, and $P<0.05$ for the chelation impact domain (Table 5).

Post hoc analyses with the Dunnett-t test after Bonferroni correction revealed that patients with fair health experienced significantly lower quality in the disease and symptoms domain than patients with good (mean difference $=-12.11$; $P<0.05$ ), very good (mean difference $=-26.08 ; P<0.001$ ), and exceptional health (mean difference $=-28.56 ; P<0.001$ ). They also experienced significantly lower quality in the 
Table 4 (Continued)

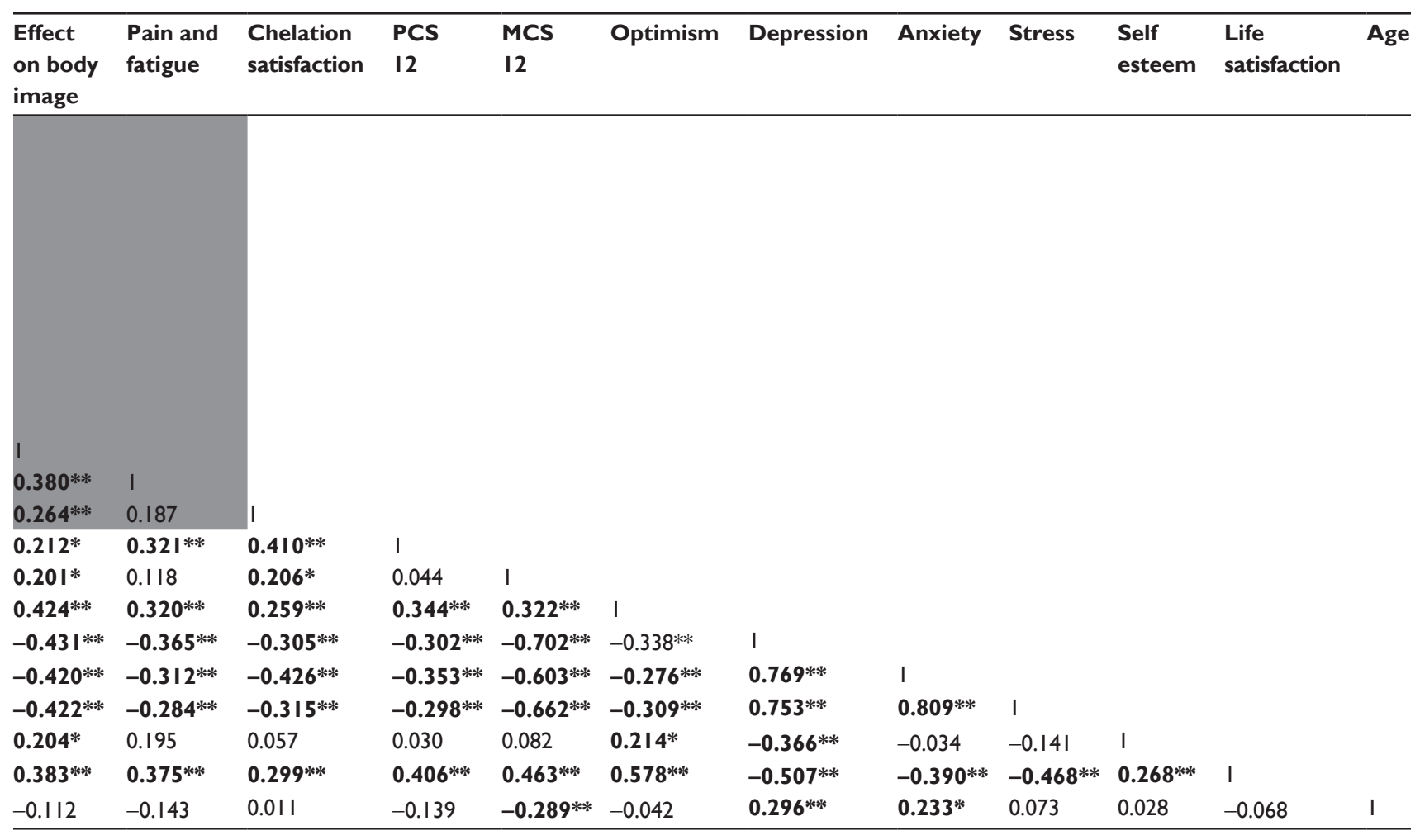

transfusion domain than patients with very good $(P<0.05)$ and exceptional health $(P<0.05)$. Similar findings were obtained for the psychosocial domain where patients with fair health experienced significantly lower quality than patients with very good $(P<0.05)$ and exceptional $(P<0.001)$ health. Finally, in the total STQOLI, patients with fair health had significantly lower scores than patients with very good (mean difference $=-15.82 ; P<0.05)$ and exceptional (mean difference $=-19.21 ; P<0.05)$ health. The Bonferroni correction revealed a significant difference in the mean scores between patients with moderate health and patients with very $\operatorname{good}(P<0.05)$ and exceptional health $(P<0.05)$.

Depression, anxiety, and stress had a significant and strong negative correlation with the psychosocial domain

Table 5 One-way ANOVA between general health and the domains of Specific Thalassemia Quality of Life Instrument (STQOLI)

\begin{tabular}{llllll}
\hline $\begin{array}{l}\text { General } \\
\text { health }\end{array}$ & $\begin{array}{l}\text { Disease and symptoms } \\
\text { mean (SD) }\end{array}$ & $\begin{array}{l}\text { Transfusion impact } \\
\text { mean (SD) }\end{array}$ & $\begin{array}{l}\text { Psychosocial impact } \\
\text { mean (SD) }\end{array}$ & $\begin{array}{l}\text { Chelation impact } \\
\text { mean (SD) }\end{array}$ & $\begin{array}{l}\text { Total STQOLI } \\
\text { mean (SD) }\end{array}$ \\
\hline Bad & $*$ & $*$ & $*$ & $*$ & $*$ \\
Fair & $40.6(I 2.3)$ & $51.2(11.8)$ & $58(15.6)$ & $68.8(7.3)$ & $57.4(13.3)$ \\
Good & $52.7(10.4)$ & $61.5(15.1)$ & $59.9(11.2)$ & $71.2(11.8)$ & $62.8(6.2)$ \\
Very good & $66.6(9.1)$ & $69.1(17.9)$ & $76.6(11.3)$ & $79.2(10.3)$ & $73.2(9.3)$ \\
Exceptional & $69.1(12.5)$ & $77.3(14.5)$ & $79.8(15.8)$ & $81(12.5)$ & $76.6(11.6)$ \\
Total & $36.9(12.7)$ & $68.4(17.4)$ & $72.3(14.8)$ & $77.3(11.7)$ & $71.4(10.8)$ \\
P-value & $\mathbf{0 . 0 0 1}$ & $\mathbf{0 . 0 0 1}$ & $\mathbf{0 . 0 0 0}$ & $\mathbf{0 . 0 5}$ & $\mathbf{0 . 0 0 1}$ \\
F & 22.17 & 5.79 & 17.59 & 4.61 & 10.23 \\
\hline
\end{tabular}

Notes: Statistically significant differences $P<0.00$ I, $P<0.0$ I, and $P<0.05$ according to one-way analysis of variance are in bold; *no patient chose the "Bad" general health option, hence it was omitted from the analysis.

Abbreviations: ANOVA, analysis of variance; SD, standard deviation. 
$\left(\mathrm{r}_{\text {depression }}=-0.680, \mathrm{r}_{\text {anxiety }}=-0.631\right.$, and $\mathrm{r}_{\text {stress }}=-0.664$; $P=0.001)$ as expected, and moderate correlation with the other subdomains of the STQOLI (Table 4). Life satisfaction was correlated significantly with all subdomains, something that was expected since QoL is a relevant construct with life satisfaction.

Self-esteem, which is a characteristic of personality, had no correlation with the STQOLI domains, but a small correlation with the effect in body image factor $(\mathrm{r}=0.205$; $P<0.05$ ), something that was in favor of discriminant validity for the new questionnaire, since QoL is a completely different construct than self-esteem.

Optimism, on the other hand, was significantly and strongly correlated with the psychosocial factor $(\mathrm{r}=0.524$; $P=0.001$ ), something that was expected since dispositional optimism has been found to be a significant predictor of mental health, ${ }^{71}$ while it had a weak correlation with the rest of the domains.

\section{Sex, education, and location comparisons}

Bivariate analyses ( $t$-test, ANOVA, and Pearson's and Spearman's correlation coefficients as appropriate) were then performed to evaluate the relationships between independent variables and HRQOL, as it was measured with the four domains of the new measurement. The $t$-test for independent samples was employed to compare means. The equality of variances required for the $t$-test was established by Levene's test. Where the variances differed, the test statistic $t$ and the error probability $P$ were assessed based on the corrected degrees of freedom. The level of significance was set at $P=0.05$.

Males reported statistically significantly lower QoL in the disease and symptoms domain $(t=-2.588 ; P<0.05)$ and in the psychosocial domain $(P<0.05)$ compared to women (Table 6). Patients that had had a splenectomy reported statistically significantly lower QoL in the disease and symptoms domain $(t=-3.226 ; P<0.05)$ than patients without a splenectomy (Table 6 ). Results showed no significant differences $(P>0.05)$ in terms of place of residence, marital status, and education in the four subdomains of the questionnaire (Table 6).

Significant overall differences were observed in the chelation therapy domain $(P<0.05)$ between the three categories of chelation therapy, which is in agreement with the literature. ${ }^{72}$ Post hoc analyses with the Dunnett-t test after Bonferroni correction revealed that patients under subcutaneous chelation therapy experienced significantly lower quality in the chelation impact domain than patients under oral (mean difference $=-16.11 ; P<0.05)$ and combination therapy (mean difference $=-16.57 ; P<0.05)($ Figure 1$)$.

Finally, ANOVA was used to identify significant differences in quality of life between the three different age categories of the sample. Analysis showed significant overall differences in the disease and symptoms domain $\mathrm{F}([2118]=13.219, P<0.001)$ between the three age groups (18-35, 36-50, and 50-plus) as in the transfusion domain F $([2118]=7.455, P<0.05)$. Post hoc analyses with the Dunnett's $t$-test after Bonferroni correction revealed that patients $>50$ years of age experienced significantly lower QoL, both in the disease and symptoms domain $(P<0.001)$, as well as in the transfusion domain $(P<0.05)$ (Table 6).

\section{Interpretation of the measurement}

The scores for each domain were calculated by adding the answers to all the items in each domain. A linear transformation was then carried out, so that the scoring scale for each domain was standardized between 0 and 100 , with a score of 100 indicating the highest level of QoL. The present QoL was assessed by patient response in each domain. The sum of every domain was transformed in a 0-100 scale in order to be easily compared with global measurements and especially with SF-12, where scores were calculated using norm-based scoring (mean 50; SD 10$)^{73}$ and reported for physical and mental dimensions on a 0-100 scale, from worst to best QoL (SF-36 and SF-12). ${ }^{47,64}$

We assumed that $10 \%$ of the total score for each subscale means that QoL is affected, and a score $<50$ means that QoL is severely affected in each domain, since we set 100 to be the score for perfect QoL, for both the total score of the questionnaire and the four subscales, as is measured in most of the QoL measures. Overall QoL, as it was valued with the total score of the STQOLI measurement, was affected $(<90 \%)$ in $97.9 \%$ of patients and severely affected $(<50 \%)$ in only $3.2 \%$ of patients.

QoL assessed in each domain showed the following results: In the disease and symptom domain, $81 \%$ had QoL $<90 \%$ (the total score was $<90$ ) and 6.4 had $<50$. In the chelation therapy domain, $94.7 \%$ had a score $<90$ and $28.1 \%$ had a score $<50$, while in the psychosocial domain, the respective percentages were $85.9 \%$ and $8.1 \%$ and were $98.6 \%$ and $27.4 \%$ in the transfusion domain.

\section{Discussion}

QoL is strongly related to an individual's perception of his or her life situation. Therefore, different people will have different perceptions of the effect of thalassemia in their lives. When assessing HRQOL, one should consider 
Table 6 One-way ANOVA and t-test for the categorical variables of the sample

\begin{tabular}{|c|c|c|c|c|c|c|}
\hline & $\mathbf{N}$ & $\begin{array}{l}\text { Disease and } \\
\text { symptoms domain } \\
\text { Mean (SD) }\end{array}$ & $\begin{array}{l}\text { Transfusion } \\
\text { Impact domain } \\
\text { Mean (SD) }\end{array}$ & $\begin{array}{l}\text { Psychosocial } \\
\text { impact domain } \\
\text { Mean (SD) }\end{array}$ & $\begin{array}{l}\text { Chelation } \\
\text { impact domain } \\
\text { Mean (SD) }\end{array}$ & $\begin{array}{l}\text { Total } \\
\text { STQOLI } \\
\text { Mean (SD) }\end{array}$ \\
\hline \multicolumn{7}{|l|}{ Sex } \\
\hline Males & 34 & $58.1(11.2)$ & $70.6(16.3)$ & $67.7(13.8)$ & $76.2(I I .4)$ & $69.2(9.9)$ \\
\hline Females & 94 & $64.8(12.9)$ & $67.5(17.9)$ & 71.1 (17.8) & $65.8 \pm 17.5$ & 72.4 (II.I) \\
\hline$P$-value & & 0.011 & NS & 0.38 & NS & NS \\
\hline \multicolumn{7}{|l|}{ Education } \\
\hline Elementary & 16 & $68.3(11)$ & $54.3(20.3)$ & $71.0(10.9)$ & $64.4(17.4)$ & $65.1(8.8)$ \\
\hline $\begin{array}{l}\text { High school/senior } \\
\text { high school }\end{array}$ & 45 & $74.8(10)$ & $62.6(15.7)$ & $73.5(13.1)$ & $64.1(16.1)$ & $69.4(8.9)$ \\
\hline Pre-graduate & 58 & $77.6(15.2)$ & $64.3(17.1)$ & $74.0(16.1)$ & $62.6(19)$ & $70.8(12.4)$ \\
\hline Postgraduate & 7 & $82.6(15.8)$ & $68.6(10.9)$ & $83.1(12.3)$ & $68.6(17.5)$ & $74.9(11.1)$ \\
\hline Total & 126 & 75.7 (I 3.4$)$ & $62.6(17)$ & $73.9(14.4)$ & $63.6(17.5)$ & $69.9(10.9)$ \\
\hline$P$-value & & NS & NS & NS & NS & NS \\
\hline \multicolumn{7}{|l|}{ Place of residence } \\
\hline Inside Athens & 102 & $75.4(13.5)$ & $61.6(16.8)$ & $72.7(14.5)$ & $63(17.4)$ & $68.9(10.7)$ \\
\hline Outside Athens & 22 & $75.8(13.1)$ & $64.4(20.1)$ & $78.9(13.6)$ & $70.2(18.6)$ & $74.9(11.6)$ \\
\hline$P$-value & & NS & NS & NS & NS & NS \\
\hline \multicolumn{7}{|l|}{ Marital status } \\
\hline Single & 71 & $75.8(14.1)$ & $63.4(16.8)$ & $74.4(14.1)$ & $61.5(16.4)$ & $69.6(10.9)$ \\
\hline Married & 48 & $75.6(12.7)$ & $60.5(18)$ & $74.6(13.9)$ & $66.5(19.8)$ & $69.9(11.8)$ \\
\hline Divorced & 9 & $74.9(12.2)$ & $60(18.3)$ & $65.0(17.2)$ & 68.7 (II.7) & $69.8(3.9)$ \\
\hline Total & 128 & 75.7 (13.3) & $62.1(17.2)$ & $73.8(14.4)$ & $64.0(17.6)$ & $69.7(10.9)$ \\
\hline$P$-value & & NS & NS & NS & NS & NS \\
\hline \multicolumn{7}{|l|}{ Chelation treatment } \\
\hline Subcutaneous & 7 & $65.3(9.3)$ & $77.7(12.8)$ & $72.3(9.9)$ & $61.4(20.4)$ & $65.6(13.7)$ \\
\hline Per os & 59 & $64.3(12.7)$ & $70.3(17.9)$ & $72.3(15.8)$ & $77.5(8.2)$ & $72.4(10.9)$ \\
\hline Combination & 60 & $61.2(13.2)$ & $65.3(16.9)$ & $73.3(14.2)$ & $77.9(13.4)$ & $70.8(10.6)$ \\
\hline Total & 126 & $62.9(12.8)$ & $68.4(17.4)$ & $72.8(14.6)$ & $77.3(11.7)$ & $71.4(10.8)$ \\
\hline$P$-value & & NS & NS & NS & 0.17 & NS \\
\hline Yes & 39 & $57.8(12.5)$ & $64.9(17.4)$ & $71.1(16)$ & $77.9(12.8)$ & $68.4(12.1)$ \\
\hline \multicolumn{7}{|l|}{ Splenectomy } \\
\hline No & 80 & $65.5(12.2)$ & $69.8(17.4)$ & $73.5(14.2)$ & 76.9 (II.2) & $72.7(10)$ \\
\hline$P$-value & & 0.002 & NS & NS & NS & NS \\
\hline \multicolumn{7}{|l|}{ Age } \\
\hline $18-35$ & 35 & $68.1(9.8)$ & $72.2(16.9)$ & $72.9(12.8)$ & $77.5(13.1)$ & $72.4(9.9)$ \\
\hline $36-50$ & 70 & $62.3(13.3)$ & $67.1(16.3)$ & $72.8(16.8)$ & 76.3 (II.9) & 7I.I (II.5) \\
\hline $50+$ & 23 & $50.2(12.1)$ & $53(20)$ & $65(6.3)$ & $80.6(8.7)$ & $65.6(10.5)$ \\
\hline Total & 128 & $63.1(12.9)$ & $67.3(17.2)$ & 72.1 (I5.I) & $76.9(12.1)$ & $71.2(I I)$ \\
\hline$P$-value & & 0.001 & 0.015 & NS & NS & NS \\
\hline
\end{tabular}

Notes: Student's $t$-test or analysis of variance with the Dunnett method after Bonferroni correction for multiple comparisons was performed.

Abbreviations: ANOVA, analysis of variance; NS, not significant for P-values > 0.05; SD, standard deviation; STQOLI, Specific Thalassemia Quality of Life Instrument.

the patient's views of his or her own health and wellbeing in the areas of physical, psychological, and social functioning. ${ }^{74}$

An assessment of an individual's HRQOL incorporates his or her appraisal of both the effects of his or her clinical diagnosis, as well as treatment side effects, and can provide important information for optimizing medical treatment, such as chelation therapy. ${ }^{75-78}$ Therefore, accurate HRQOL assessment can assist in making patients' priorities explicit to both patients and their health professionals, and can signify an important factor in guiding care decisions.
Current measures evaluate patients' HRQOL across a number of domains; however, they do not explicitly evaluate patients' priorities or preferences, and thus may be unable to precisely identify priorities in care. Further, patients' HRQOL domain preferences may change over time, depending on treatment progression, as can happen in chelation therapy with per os treatment, and life situations, and can differ as a function of demographic and disease characteristics. The ability to more precisely and efficiently assess patients' HRQOL in a clinical setting is therefore vital in providing broad and individualized medical care, and thus 


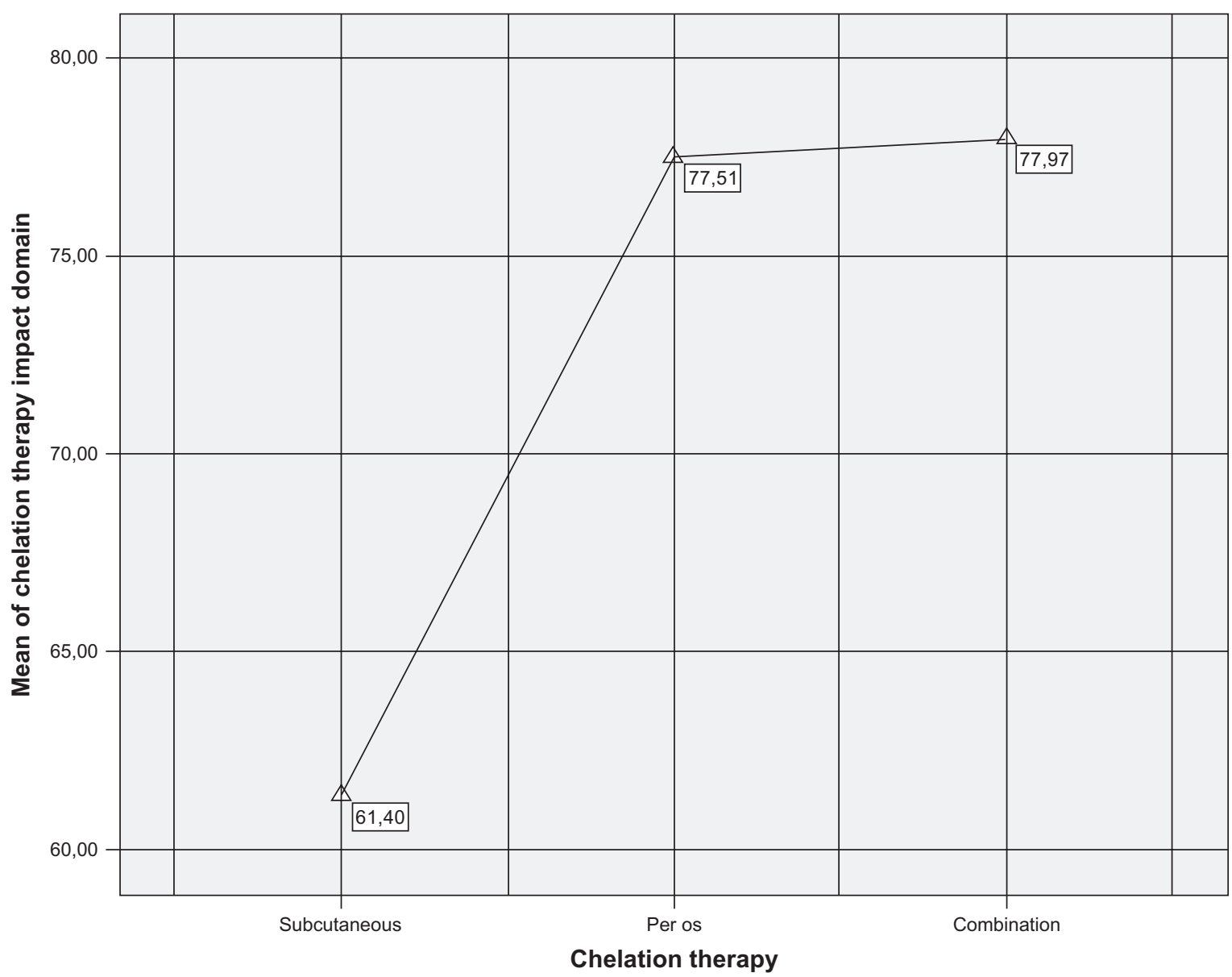

Figure I Differences in the chelation impact domain between the three chelation therapies from ANOVA. Abbreviation: ANOVA, analysis of variance.

emphasizes the importance of assessing the accuracy and validity of current measures.

Numerous measures have been developed to assess patients' HRQOL, ${ }^{65,75,79,80}$ but most of them are generic and are not designed for the needs of thalassemia patients. Since there is no specific instrument for measuring QoL in thalassemia, this study's goal was to develop and validate the new STQOLI questionnaire by attempting to assess domain preferences as they relate to the current situation of the patient.

This study supports the reliability and validity of the Greek version of the STQOLI. The validation was based on data provided by 128 patients, using exploratory factor analysis. The results show that construct validity, internal consistency, and concurrent validity of the Greek version of the STQOLI, and their corresponding subscales were generally supported by our population. Thus, the 41 -item STQOLI seems to be a valid tool in assessing HRQOL for patients with thalassemia.

The sample size of this study was 128 patients, which is a good number for the factor analysis procedure and the 41-item questionnaire. It is estimated that there are 2900 thalassemia patients in Greece. A general rule of thumb is that one should have at least 50 observations and at least five times as many observations as variables $;{ }^{81}$ thus, if we had wanted to apply factor analysis on the whole questionnaire, we would have needed a sample size of 205 patients.

However, as Tucker and MacCallum suggest, research in psychology often includes a number of steps which, though they may not be explicitly stated, can be recognized clearly and which represent integral parts of the research process. ${ }^{82}$ The first step is the identification of the domain and population of interest. Given a domain and population of interest, the researcher selects the domain variables that are to be measured. These variables are the surface attributes that may be observed and measured. For example, in our research, in the psychosocial impact domain, we wanted to construct a test to measure distinct kinds of attributes, such as mental health, self-image, and subjective feelings about the disease. In the transfusion domain, we wanted to measure both the impact of transfusion on QoL and the way a patient feels that transfusion is affecting his or her life. Each 
of these tests represents a surface attribute. Clearly, in any given domain, it would be possible to identify and measure a vast array of surface attributes. A set of surface attributes measured in a given study will be referred to as a battery of surface attributes.

According to the same authors, factor analysis involves a set of techniques designed to identify order and structure in such data by providing a parsimonious and meaningful explanation for the observed variation and covariation in surface attributes. ${ }^{82}$

Assuming that each surface attribute has internal attributes, meaning the unobservable characteristics of people that differ in extent or to a degree and are more fundamental than surface attributes, we took the decision to first explore each surface attribute with a separate factor analysis to determine the latent variables of each domain. The decision was made since the four domains are not subdomains but are different surface attributes that affect QoL and can be used independently as a single measure or as a part of a battery. A second EFA was then applied in the total questionnaire following the rule of thumb of Stevens ${ }^{81}$ based on sample size and keeping loadings higher than 0.448 for the 128 patients.

Item deletion (which is one reason to apply factor analysis) was already decided upon after a first CFA and the evaluation of "Cronbach's- $\alpha$ if item deleted" in the 60 and 50 items, respectively, with the consent of the experts committee.

Nevertheless, both factor analyses in the whole sample and for each attribute independently had the same factor loadings for the chelation therapy, transfusion impact, and disease and symptoms domain. There was a slight difference in the psychosocial factor since the questionnaire as a whole has different questions concerning the psychological effect in transfusion, chelation therapy, social life, and body image. Only item 36, regarding splenectomy, could have been excluded from the questionnaire since it loaded differently in the two EFAs, but according to the experts committee, it was an important item, so it remained in the questionnaire.

In terms of content and face validity, both are optimized by a wide range of individuals involved. ${ }^{67}$ The wide number of people involved in the experts committee optimizes content, and the wide number of people involved in content's transformation into a questionnaire and in pilots demonstrates that this content has been successfully transferred in the questionnaire. The fact that all five alternative response options in almost all questions were used supports this conclusion. ${ }^{83}$ Three questions with zero or only one answer in the first and last option, as well as all questions with the majority of the answers in the moderate area, were thoroughly examined and the three items referring to interferon and satisfaction with the medical and nursing staff were excluded from the questionnaire.

High reliability is usually a prerequisite for sensitivity, ${ }^{67}$ and this condition was met for the total score of the new instrument and the factors with more items. Only three factors out of the eleven that were revealed from the second factor analysis had unacceptable reliability, $>0.7$, but the items of those factors are inside the main four factors with acceptable reliability and nevertheless were higher than expected (Table 2). Furthermore, the score differences found among splenectomized patients and patients who had not had a splenectomy ${ }^{84}$ and between patients with different treatments ${ }^{72}$ are a good sign of the instrument's ability to detect existing differences among groups (sensitivity). It is reasonable to accept that these differences really exist as reported in the literature. ${ }^{72,85}$

The fact that female patients perceive their psychosocial and disease domains higher than the male patients may reflect reality rather than bias or simply chance since it has been repeatedly reported that female patients with TM survive longer than males and that the difference is due to the lower rate of cardiac disease in females. ${ }^{5,85,86}$ In addition, females tolerate iron toxicity better, possibly as an effect of reduced sensitivity to chronic oxidative stress. ${ }^{87}$

The results that were found both from the ANOVA and the Pearson correlation relating to age differences are also in favor of the discriminant validity of the new measurement since it is common knowledge that the older a patient is, the more complications he or she has from the disease. We can also assume that if a patient is having regular transfusions, he or she eventually gets tired from the continuing procedure since it is known that patients feel more distress from their treatments than from their illness itself. ${ }^{88}$

In terms of interpretation, QoL for each patient was given as a summary score between 0\% (worst QoL) and 100\% (best possible QoL) and four sub scores for each individual domain in the same order. This concept can be very useful for the serial assessment of QoL among patients with TM and interventions can be designed in various domains that improve QoL in thalassemia patients.

It is known through research that as the clinical burden increases, so does the psychological burden. ${ }^{54}$ The results of the present study are consistent with the literature since we found negative significant correlations between STQOLI and depression, anxiety, stress, and age, meaning that the better QoL a patient has, the less anxious, depressed, and stressed 
he or she is, and the younger a patient is, the better his or her QoL. Further research is warranted to continue the qualitative and quantitative study of QoL using validated instruments in patients with thalassemia in order to advance our understanding of the issues and to improve patient QoL.

Given that minimal literature was available, we relied on patient and clinician interviews. It is a positive aspect that the clinicians interviewed had experience primarily with iron overload in thalassemia and sickle cell disease.

As previously mentioned, CIT analysis was used to identify important factors in QoL. We have discussed the advantages of this technique, but we must also refer to its disadvantages. A first problem comes from the type of reported incidents. CIT analysis relies on events being remembered by users and also requires the accurate and truthful reporting of these events. Since critical incidents often rely on memory, incidents may be imprecise or may even go unreported. The method also has a built-in bias toward incidents that happened recently, since these are easier to recall. Finally, respondents may not be accustomed or willing to take the time to tell (or write) a complete story when describing a critical incident.

In order to avoid these disadvantages, we also used semistructured interviews and asked the patients to respond to each factor that we found in the literature review.

This study has several limitations, including a small sample size and a homogeneous patient population (ie, Caucasian patients with TM). Our conclusions can only be applied to patients with TM, which were the largest group of patients studied. Another limitation was the poorly targeted population. Patients on the poor side of the QoL spectrum were missing.

Although the purpose of this questionnaire was to explore QoL in adults and not in children, who are the next target group of our research, patients came from an adult transfusion center and there were no patients between 18 and 19 years old while the research was in progress, a fact that may add a bias in the sample.

Another limitation would be that the questionnaire is geographically bounded; although Greek is the official language of our country, diverse cultures coexist within Greece. Therefore, it would be important to carry out a cross-cultural adaptation before it is used in other countries, and also to validate the adapted questionnaire as if it were a new one.

In the current study, we developed the STQOLI based on experiences among an adult population with a mean age of 28-47 years. However, there may be added value to evaluating the experiences and QoL in thalassemia among pediatric and adolescents populations, and incorporating them into the STQOLI.

Future studies with the STQOLI should examine patients with other types of Cooley disorders and different ethnicities in a larger population because dimensionality examinations of questionnaires are influenced by the study population, and the greater the sample size, the greater the power in detecting misfit.

Additional qualitative research with pediatrics would be warranted, whereas with adolescents, a two-stage process of concept elicitation and CIT analysis may be sufficient. We recommend further qualitative and empirical studies to assess the impact of thalassemia on QOL using this instrument in more patients to explore the global psychometric properties of the questionnaire.

Finally, we should add that QoL assessment involves a class of measurement fundamental to many aspects of health care planning and outcomes research. It is relevant for assessing symptoms, side effects of treatment, disease progression, satisfaction with care, quality of support services, unmet needs, and appraisal of health and health care options, and STQOLI is the first and only (to our knowledge) questionnaire for thalassemia patients that allows the decision of how well the patient feels to be reported by the patient.

Patient self-reporting, as in the STQOLI, is the most desirable, and often, the only way to obtain this critical information. Thus, accurate and meaningful measures of the various dimensions of QoL are vitally important. In addition, patient-reported outcomes have become increasingly important tools for understanding how various conditions affect patients. Both the US Food and Drug Administration and the Committee for Medicinal Products for Human Use of the European Medicines Agency emphasize the value of patient-reported outcome measures in identifying and quantifying a patient's perspective on his or her disease and its treatments. STQOLI is such a tool for thalassemia patients to express their perspectives.

\section{Conclusion}

Although there are some limitations to the study, as mentioned above, the results show that construct validity, internal consistency, and concurrent validity of the Greek version of the STQOLI, and its corresponding subscales, were generally supported by our population; thus, the 41-item STQOLI seems to be a valid tool in assessing HRQOL for patients with thalassemia. 


\section{Acknowledgments}

We would like to thank all the experts on the experts committee who assisted in the development of the questionnaire as well as the patients who took part in this study. We would like to thank Qualitis Ltd (Athens, Greece) for English language editing. Thanks are due to anonymous reviewers for their comments on an earlier version of this paper.

STQOLI $^{\circ}$ is protected by international copyright with all rights reserved by George N Lyrakos. Do not use without permission. For information on, or permission to use STQOLI $^{\circ}$ and/or its translation, please contact the corresponding author.

\section{Authors' contributions}

GL conceived of the study, coordinated and participated in the design of the study, performed the statistical analyses, and drafted the manuscript. DM, MD, and AE participated in the design. All authors read and approved the final manuscript.

\section{Disclosure}

The authors report no conflicts of interest in this work.

\section{References}

1. Weatherall DJ. The thalassaemias: the role of molecular genetics in an evolving global health problem. Am J Hum Genet. 2004;74(3): 385-392.

2. Newacheck PW, Taylor WR. Childhood chronic illness: prevalence, severity, and impact. Am J Public Health. 1992;82(3):364-371.

3. Dubey AP, Parakh A, Dublish S. Current trends in the management of beta thalassemia. Indian J Pediatr. 2008;75(7):739-743.

4. Cohen A. Management of iron overload in pediatric patients. Hematol Oncol Clin North Am. 1987;1(3):521-544.

5. Borgna-Pignatti C, Rugolotto S, De Stefano P, et al. Survival and complications in patients with thalassemia major treated with transfusion and deferoxamine. Haematologica. 2004;89(10):1187-1193.

6. Olivieri NF, Nathan DG, MacMillan JH, Wayne AS, Liu PP, McGee A. Survival in medically treated patients with homozygous beta-thalassemia. New Engl J Med. 1994;331(9):574-578.

7. Porter J, Davis BA. Monitoring chelation treatment to achieve optimal outcome in the treatment of thalassemia. Best Pract Res Clin Haematol. 2000;15(2):329-368.

8. Zurlo MG, De Stefano P, Borgna-Pignatti C, et al. Survival and causes of death in thalassemia major. Lancet. 1989;2(8653):27-30.

9. Weatherall DJ, Clegg JB. Inherited hemoglobin disorders: an increasing global health problem. Bull World Health Organ. 2001;79(8): 704-712.

10. Newacheck PW, Strickland B, Shonkoff JP, et al. An epidemiologic profile of children with special health care needs. Pediatrics. 1998; 102(1 Pt 1):117-123.

11. Telfer P, Constantinidou G, Andreou P, Christou S, Modell B, Angastiniotis M. Quality of life in thalassemia. Ann NY Acad Sci. 2005;1054: 273-282.

12. Varni JW, Burwinkle TM, Lane MM. Health-related quality of life measurement in pediatric clinical practice: an appraisal and precept for future research and application. Health Qual Life Outcomes. 2005;3:34.

13. Di Palma A, Vullo C, Zani B, Facchini A. Psychosocial integration of adolescents and young adults with thalassemia major. Ann N Y Acad Sci. 1998;850:355-360.
14. Politis C, Di Palma A, Fisfis M, et al. Social integration of the older thalassemia patient. Arch Dis Child. 1990;65(9):984-986.

15. Spanos T, Ladis V, Palamidou F, et al. The impact of neocyte transfusion in the management of thalassaemia. Vox Sang. 1996;70(4): 217-223.

16. Kuo HT, Tsai MY, Peng CT, Wu KH. Pilot study on the "quality of life" as reflected by psychosocial adjustment of children with thalassemia major undergoing iron-chelating treatment in western Taiwan. Hemoglobin. 2006;30(2):291-299.

17. Caocci G, Efficace F, Ciotti F, et al. Prospective assessment of healthrelated quality of life in pediatric patients with beta-thalassemia following hematopoietic stem cell transplantation. Biol Blood Marrow Transplant. 2011;17(6):861-866.

18. Clarke SA, Skinner R, Guest J, et al. Health-related quality of life and financial impact of caring for a child with thalassemia major in the UK. Child Care Health Dev. 2010;36(1):118-122.

19. Pakbaz Z, Treadwell M, Yamashita R, et al. Quality of life in patients with thalassemia intermedia compared to thalassemia major. Ann $N Y$ Acad Sci. 2005;1054:457-461.

20. Musallam KM, Khoury B, Abi-Habib R, et al. Health-related quality of life in adults with transfusion-independent thalassaemia intermedia compared to regularly transfused thalassemia major: new insights. Eur J Haematol. 2011;87(1):73-79.

21. Messina G, Colombo E, Cassinerio E, et al. Psychosocial aspects and psychiatric disorders in young adult with thalassemia major. Intern Emerg Med. 2008;3(4):339-343.

22. Jafari H, Lahsaeizadeh S, Jafari P, Karimi M. Quality of life in thalassemia major: reliability and validity of the Persian version of the SF-36 questionnaire. J Postgrad Med. 2008;54(4):273-275.

23. Scalone L, Mantovani LG, Krol M, et al. Costs, quality of life, treatment satisfaction and compliance in patients with beta-thalassemia major undergoing iron chelation therapy: the ITHACA study. Curr Med Res Opin. 2008;24(7):1905-1917.

24. Payne KA, Rofail D, Baladi JF, et al. Iron chelation therapy: clinical effectiveness, economic burden and quality of life in patients with iron overload. Adv Ther. 2008;25(8):725-742.

25. Vardaki MA, Philalithis AE, Vlachonikolis I. Factors associated with the attitudes and expectations of patients suffering from beta-thalassaemia: a cross-sectional study. Scand J Caring Sci. 2004;18(2):177-187.

26. Borgna-Pignatti $\mathrm{C}$. The life of patients with thalassemia major. Haematologica. 2010;95(3):345-348.

27. Kuo HT, Peng CT, Tsai MY. Pilot study on parental stress and behavioral adjustment to the thalassemia major disease process in children undergoing iron-chelation in western Taiwan. Hemoglobin. 2006;30(2):301-309.

28. Caro JJ, Ward A, Green TC, et al. Impact of thalassemia major on patients and their families. Acta Haematol. 2002;107:150-157.

29. Cao A. Quality of life and survival of patients with beta-thalassemia major. Haematologica. 2004;89(10):1157-1159.

30. Mikelli A, Tsiantis J. Brief report: Depressive symptoms and quality of life in adolescents with b-thalassaemia. $J$ Adolescence. 2004;27: 213-216.

31. Ward A, Caro JJ, Green TC, et al. An international survey of patients with thalassemia major and their views about sustaining life-long desferrioxamine use. BMC Clin Pharmacol. 2002;2:3.

32. Arboretti R, Tognoni G, Alberti D; Italian Colaborative Group on Thalassarmia. Pharmacosurveillance and quality of care of thalassemia patients. A large scale epidemiological survey. Eur J Clin Pharmacol. 2001;56(12):915-922.

33. World Health Organization. Constitution of the World Health Organization: Basic Document. New York: World Health Organization; 1948.

34. Guidance for Industry: Patient-reported outcome measures: Use in medical product development to support labeling claims [draft guidance]. U.S. Department of Health and Human Services, Food and Drug Administration, Center for Drug Evaluation and Research (CDER), Center for Biologics Evaluation and Research (CBER), Center for Devices and Radiological Health (CDRH); 2006 
35. De Sanctis V, Roos M, Gasser T, Fortini M, Raiola G, Galati MC. Impact of long-term iron chelation therapy on growth and endocrine functions in thalassaemia. J Pediatr Endocrinol Metab. 2006;19:471-480.

36. Abetz L, Baladi J-F, Jones P, Rofail D. The impact of iron overload and its treatment on quality of life: results from a literature review. Health Qual Life Outcomes. 2006;4:73.

37. Guyatt GH, Kirschner B, Jaeschke R. Measuring health status: what are the necessary measurement properties? J Clin Epidemiol. 1992;45:1341-1345.

38. Medical Outcomes Trust. Trust introduces new translation criteria. Trust Bulletin. 1997;5:1-4. Available from: http://www.outcomes-trust.org/ bulletin/0797blltn.htm. Accessed 20 August, 2007.

39. Guillemin F, Bombardier C, Beaton D. Cross cultural adaptation of health-related quality of life measures: literature review and proposed guidelines. J Clin Epidemiol. 1993;46(12):1417-1432.

40. Benet V, Waller NG. The Big Seven factor model of personality description; evidence for its cross-cultural generality in a Spanish sample. J Pers Soc Psychol. 1995;69(4):701-718.

41. de Vaus DA. Surveys in Social Research. London: UCL Press; 1991.

42. Flanagan JC. The critical incident technique. Psychol Bull. 1954;51(4): 327-359.

43. Strauss AL. Qualitative Analysis for Social Scientists. New York: Cambridge University Press; 1987.

44. Ismail A, Campbell MJ, Ibrahim HM, Jones GL. Health related quality of life in Malaysian children with thalassaemia. Health Qual Life Outcomes. 2006;4:39.

45. Shaligram D, Girimaji SC, Chaturvedi SK. Psychological problems and quality of life in children with thalassemia. Indian J Pediatr. 2007;74(8):727-730.

46. Abetz L, Baladi J, Jones P, Rofail D. The impact of iron overload and its treatment on quality of life: results from a literature review. Health Qual Life Outcomes. 2006;4:73.

47. Fitzpatrick R. Fitzpatrick R. Surveys of patient satisfaction: II - designing a questionnaire and conducting a survey. BMJ. 1991;302(6785): 1129-1132.

48. Streiner DL, Norman GR. Health Measurement Scales - A Practical Guide to Their Development and Use. 4th ed. Oxford: Oxford University Press; 2008.

49. Ware JE, Kosinski M, Keller SD. SF-12: an even shorter health survey. Med Outcomes Trust Bull. 1996;4(1):2.

50. Ware JE, Kosinski M, Keller SD. A 12-item short-form health survey. Construction of scales and preliminary tests of reliability and validity. Med Care. 1995;34(3):220-233.

51. Lyrakos GN, Arvaniti C, Smyrnioti M, Kostopanagiotou G. Translation and validation study of the depression anxiety stress scale in the Greek general population and in a psychiatric patient's sample. Eur Psychiatry. 2011;26(Supp1 1):1731.

52. Lyrakos G, Damigos D, Mavreas V, Georgia K, Dimoliatis I. A translation and validation study of the Life Orientation TestRevised in the Greek-speaking population of nurses among three hospitals in Athens and Ioannina. Soc Indic Res. 2010;95(1): 129-142.

53. Rosenberg M. Society and the Adolescent Self-Image. Princeton: Princeton University Press; 1965.

54. Diener E, Emmons R, Larsen J, Griffin S. The satisfaction with life scale. J Pers Assess. 1985;49(1):71-75.

55. West SG, Finch JF, Curran PJ. Structural equation models with nonnormal variables. In: Hoyle RH, editor. Structural Equation Modeling: Concepts, Issues, and Applications. Thousand Oaks: Sage Publications; 1995:56-75.

56. Curran PJ, West SG, Finch JF. The robustness of test statistics to nonnormality and specification error in confirmatory factor analysis. Psychol Methods. 1996;1(1):16-29.

57. Cronbach LJ. Coefficient alpha and the internal structure of tests. Psychometrika. 1951;16:297-334.

58. Kaiser HF. The application of electronic computers to factor analysis. Edu Psychol Meas. 1960;20:141-151.
59. Cattell RB. The scree test for the number of factors. Multivariate Behav Res. 1966;1:245-276.

60. Clark LA, Watson D. Constructing validity: Basic issues in objective scale development. Psychol Assess. 1995;7(3):309-319.

61. Nunnally JC. Psychometric Theory. 2nd ed. New York: McGraw Hill; 1978.

62. Lovibond SH, Lovibond PF. Manual for the Depression Anxiety Stress Scales. 2nd ed. Sydney: Psychology Foundation; 1995.

63. Lovibond PF, Lovibond SH. The structure of negative emotional states: comparison of the Depression Anxiety Stress Scales (DASS) with the Beck Depression and Anxiety Inventories. Behav Res Ther. 1995;33(3):335-343.

64. Scheier MF, Carver CS, Bridges MW. Distinguishing optimism from neuroticism (and trait anxiety, self-mastery, and self-esteem): a re-evaluation of the Life Orientation Test. J Pers Soc Psychol. 1994;67:1063-1078.

65. Pappa E, Kontodimopoulos N, Niakas D. Validating and norming of the Greek SF-36 Health Survey. Qual Life Res. 2005;14:1433-1438.

66. Norušis MJ. Measuring scales: reliability analysis examples. In: SPSS Inc. SPSS Professional Statistics ${ }^{T M} 7.5$ [book on CR-ROM]. NJ: Prentice Hall; 1997.

67. Fayers PM, Machin D. Quality of Life: Assessment, Analysis and Interpretation. Chichester: John Willey and Sons; 2001.

68. Kline P. A Handbook of Test Construction: Introduction to Psychometric Design. New York: Methuen; 1986.

69. Hatcher L.A Step-by-Step Approach to Using the SAS System for Factor Analysis and Structural Equation Modeling. Cary, NC: SAS Institute Inc; 1994

70. Tabachnick BG, Fidell LS. Using Multivariate Statistics. 3rd ed. New York: Harper and Collins College Publishers; 1996.

71. Lyrakos NG. Role of Dispositional Optimism in Health Related Quality of Life Among Health Care Professionals with Musculoskeletal Pain. New York: Nova Publishers; 2011.

72. Osborne RH, De Abreu Lourenço R, et al. Quality of life related to oral versus subcutaneous iron chelation: a time trade-off study. Value Health. 2007;10(6):451-456.

73. Ware JE, Kosinski M, Keller SD. SF-12: How to Score the SF-12 Physical and Mental Health Summary Scales. 2nd ed. Boston: The Health Institute, New England Medical Center; 1995.

74. Ratip S, Skuse D, Porter J, Wonke B, Yardumian A, Modell B. Psychosocial and clinical burden of thalassemia intermedia and its implications for prenatal diagnosis. Arch Dis Child. 1995;72(5): 408-412.

75. Brittenham GM, Griffith PM, Nienhuis AW, et al. Efficacy of deferoxamine in preventing complications of iron overload in patients with thalassemia major. N Engl J Med. 1994;331(9):567-573.

76. Guyatt G. Feeny D, Patrick D. Measuring health related quality of life. Ann Intern Med. 1993;118(8):622-629.

77. Nanda U, Andresen E. Health-related quality of life. A guide for the health professional. Eval Health Prof. 1998;21:179-215.

78. Oldridge N. Outcomes measurement: Health-related quality of life. Assist Technol. 1996;8(2):82-93.

79. Ware JE, Gandek B. Qverview of the SF-36 Health Survey and the international quality of life assessment (IQOLA) Project. $J$ Clin Epidemiol. 1998;51(11):903-912.

80. Ware JE, Kosinski M, Gandek B. SF-36 Health Survey: Manual and Interpretation Guide. Lincoln, RI: Quality-Metric Inc; 2003.

81. Stevens, J. Applied Multivariate Statistics for the Social Sciences. 2nd ed. Majwaw: Psychology Press; 2002.

82. Tucker LR, MacCallum RC. Exploratory Factor Analysis. 1997 [updated 2009 May 20; cited 2012 Mar 10]. Available from: http:// higherintellect.info/texts/math/Exploratory\%20Factor\%20Analysis.pdf. Accessed February 12, 2009.

83. Pappa E, Kontodimopoulos N, Niakas D. Psychometric evaluation and normative data for the Greek SF-36 health survey using a large urban population sample. Arch Hellen Med. 2006;23(2):159-166.

84. Taher AT, Musallam KM, Cappellini MD. Thalassaemia Intermedia: an Update. Mediterr J Hematol Infect Dis. 2009;1:1. 
85. Chouliaras G, Yiannoutsos CT, Berdoukas V, Ladis V. Cardiac related death in thalassaemia major: time trend and risk factors in a large Greek Unit. Eur J Haematol. 2009;82(5):381-387.

86. Telfer PT, Warburton F, Christou S, et al. Improved survival in thalassemia major patients on switching from desferrioxamine to combined chelation therapy with desferrioxamine and deferiprone. Haematologica. 2009;94(12):1777-1778.
87. Marsella M, Borgna-Pignatti C, Meloni A, et al. Cardiac iron and cardiac disease in males and females with transfusion-dependent thalassemia major: a T2* magnetic resonance imaging study. Haematologica. 2011;6:515-520.

88. Evangeli M, Mughal K, Porter JB. Which psychosocial factors are related to chelation adherence in thalassemia? A systematic review. Hemoglobin. 2010;34(3):305-321.

\section{Publish your work in this journal}

Patient Preference and Adherence is an international, peer-reviewed, open access journal focusing on the growing importance of patient preference and adherence throughout the therapeutic continuum. Patient satisfaction, acceptability, quality of life, compliance, persistence and their role in developing new therapeutic modalities and compounds to optimize clinical outcomes for existing disease states are major areas of interest. This journal has been accepted for indexing on PubMed Central. The manuscript management system is completely online and includes a very quick and fair peer-review system. Visit http://www.dovepress.com/ testimonials.php to read real quotes from published authors.

Submit your manuscript here: http://www.dovepress.com/patient-preference-and-adherence-journal 